\title{
Effects of Non-equilibrium Chemistry and Darcy-Forchheimer Flow of Pyrolysis Gas for a Charring Ablator
}

\author{
Yih-Kanq Chen $^{*}$ and Frank S. Milos ${ }^{\dagger}$ \\ NASA Ames Research Center, Moffett Field, CA 94035-1000
}

The Fully Implicit Ablation and Thermal Response code, FIAT, simulates pyrolysis and ablation of thermal protection materials and systems. The governing equations, which include energy conservation, a three-component decomposition model, and a surface energy balance, are solved with a moving grid. This work describes new modeling capabilities that are added to a special version of FIAT. These capabilities include a time-dependent pyrolysis gas flow momentum equation with Darcy-Forchheimer terms and pyrolysis gas species conservation equations with finite-rate homogeneous chemical reactions. The total energy conservation equation is also enhanced for consistency with these new additions. Parametric studies are performed using this enhanced version of FIAT. Two groups of analyses of Phenolic Impregnated Carbon Ablator (PICA) are presented. In the first group, an Orion flight environment for a proposed Lunar-return trajectory is considered. In the second group, various test conditions for arcjet models are examined. The central focus of these parametric studies is to understand the effect of pyrolysis gas momentum transfer on PICA material in-depth thermal responses with finite-rate, equilibrium, or frozen homogeneous gas chemistry. Results are presented, discussed, and compared with those predicted by the baseline PICA/FIAT ablation and thermal response model developed by the Orion Thermal Protection System Advanced Development Project.

\section{Nomenclature}

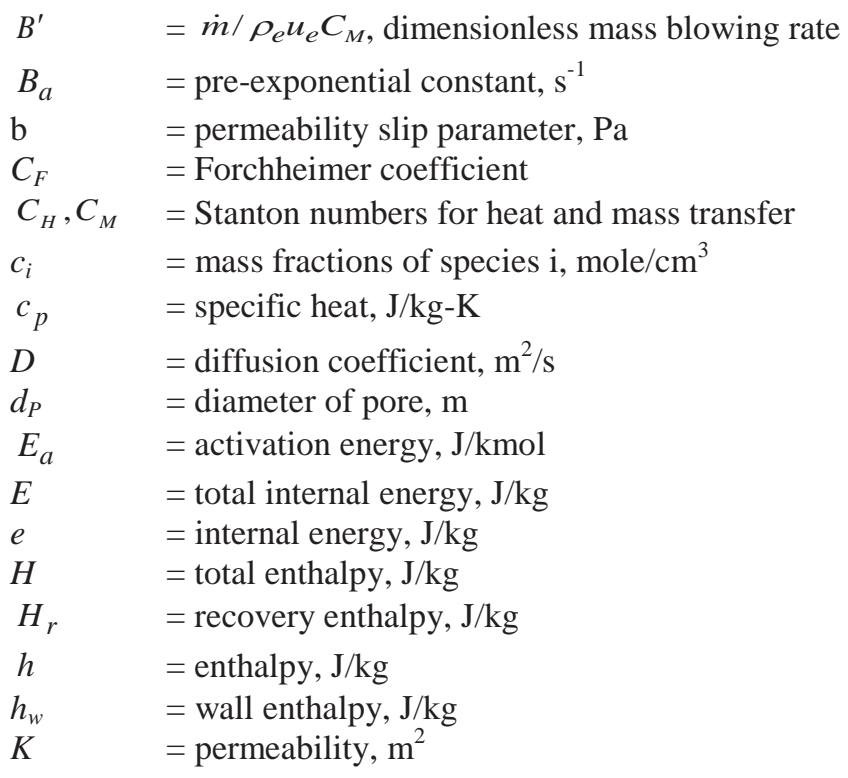

\footnotetext{
* Aerospace Engineer, Aerothermodynamics Branch, MS 230-2, Member AIAA.

${ }^{\dagger}$ Aerospace Engineer, Thermal Protection Materials Branch, MS 234-1. Senior Member AIAA.
} 


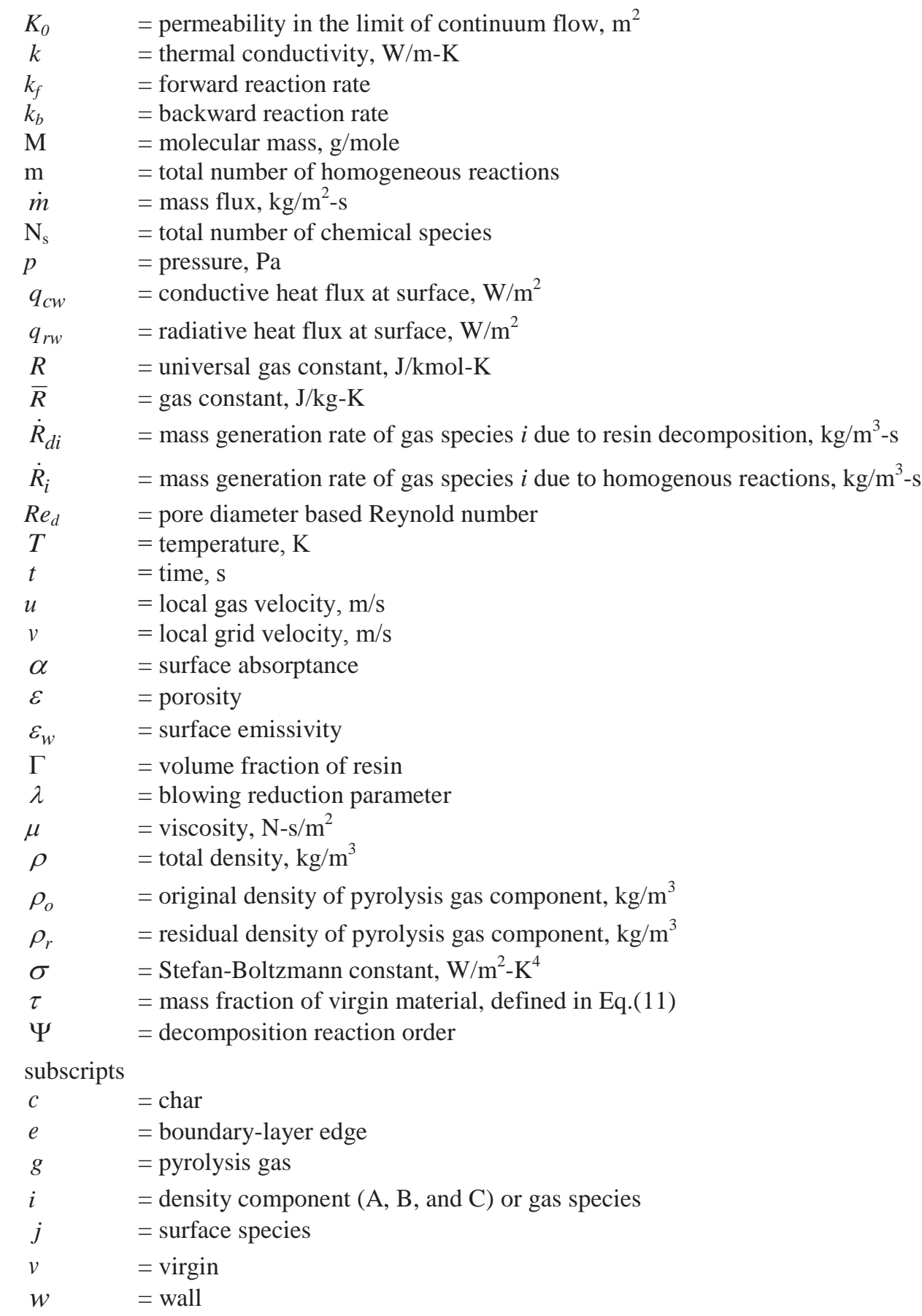

\section{Introduction}

The authors have developed a family of programs for analysis of ablative thermal protection system (TPS) materials. The Fully Implicit Ablation and Thermal response code (FIAT) ${ }^{1}$, the Two-dimensional Implicit Thermal response and Ablation code $(\mathrm{TITAN})^{2}$, and the $\underline{3}$-dimensional Finite-volume alternating direction Implicit Ablation and Thermal response code (3dFIAT) ${ }^{3}$ simulate the internal heat conduction, in-depth thermal decomposition, quasisteady pyrolysis gas flow, and surface ablation of TPS materials in one, two, and three dimensions, respectively. FIAT is widely used by NASA and industry as the one-dimensional analysis and sizing tool for spacecraft TPS materials. TITAN can analyze problems with two-dimensional or axisymmetric geometry. In some cases, a twodimensional analysis is inadequate, and a three-dimensional ablation code is required to perform a high fidelity simulation. The 3dFIAT program can analyze the thermal response of the entire heatshield of a space vehicle. The 
prediction of ablative heatshield response for a spacecraft entering the atmosphere with an angle of attack is such a case.

In this family of programs, decomposing materials are assumed to behave as three independently pyrolyzing components. Once the pyrolysis gas is formed, the gas flow is assumed to reach steady state instantaneously by ignoring the pressure and viscous resistance effects. These assumptions are generally good if the char depth is relatively thin. In such cases, there is no need to solve the momentum and species conservation equations for pyrolysis gas flow.

The non-equilibrium chemistry of pyrolysis gas inside the char layer was first studied by April et al. in $1971 .^{4}$ Since then, there have been no significant efforts made in this area to model the finite-rate homogeneous chemical reactions of pyrolysis gas. Recently, a study conducted by Ayasoufi and his coworkers attempted to examine the effect of non-equilibrium pyrolysis gas chemistry on the performance of charring ablators, ${ }^{5}$ in which the pyrolysis gas chemistry was based on the work of April. However, in Ayasoufi's work, the gas flow momentum conservation was not considered, and thus, the mass flow rate and kinetic energy of the gas could not be accurately predicted. The effect of porosity on gas flow inside a charring ablator was extensively studied by Ahn et. al. ${ }^{6}$ They solved the gas momentum equation within a carbon-phenolic heatshield of the Pioneer Venus probes for pyrolysis gas in chemical equilibrium. Recently the non-Darcy behavior of pyrolysis gas in a thermal protection system also was examined by Martin and Boyd. ${ }^{7}$

Given the large surface area within porous TPS materials, and the relatively low flow velocity, one would think that both homogeneous (gas) and heterogeneous (surface) reactions may be important, for how quickly pyrolysis gas approaches a state of chemical equilibrium. Heterogeneous reactions are important for additional complex phenomena, such as coking which was observed in the Apollo heatshield. ${ }^{8}$ However, the effect of heterogeneous reactions within pyrolyzing heatshields has been mostly neglected.

Darcy's law has limited applicability, because it only accounts for the viscous resistance of the flow at low speed. If the flow speed is not sufficiently low, then inertial contributions to the flow resistance may become noticeable. The Darcy-Forchheimer equation ${ }^{9}$ is widely used to account for the inertial effects in porous media. In this paper, we enhanced the FIAT code by including the time dependent pyrolysis gas momentum equation with the Darcy-Forchheimer terms within a porous char layer to obtain the flow velocity. Additionally, the multi-species mass conservation equations for pyrolysis gas are solved to simulate the non-equilibrium chemistry that may occur inside a char layer. The three-component decomposition model, which is based on the Thermogravimetric Analysis (TGA) data, is used to estimate the instantaneous density of resin. For non-equilibrium pyrolysis gas modeling, the homogeneous chemical reactions and associated rates similar to those developed by April et $\mathrm{al}^{4}$ are considered.

The charring thermal protection material considered in this work is Phenolic Impregnated Carbon Ablator (PICA), ${ }^{10}$ which is a low density ablator that was used as the heatshield material of Stardust Sample Return Capsule. ${ }^{11}$ The purpose of this paper is two-fold: first, to describe the details of the formulation considered in the enhanced version of FIAT, and second, to perform parametric studies to understand how the pyrolysis gas momentum transfer affects PICA material in-depth thermal response with various gas chemistry models to guide the direction of future work. The aerothermal environments used for the parametric studies are those relevant to the Orion Lunar return mission, including both flight and arcjet conditions. The predictions are presented and compared with those based on the PICA/FIAT material response model developed by Orion TPS ADP. ${ }^{12}$

\section{Governing Equations}

Under the assumption of local thermal equilibrium, the total energy conservation equation in conservative form for the combined solid-gas system inside a charring ablator is defined as:

$$
\frac{\partial}{\partial t}\left(\rho c_{p} T+\varepsilon E_{g}\right)+\nabla \cdot\left(\varepsilon \vec{u}_{g} H_{g}\right)+\nabla \cdot(k \nabla T)=\vec{v} \cdot \nabla\left(\rho c_{p} T+\varepsilon E_{g}\right)
$$

where 


$$
\begin{aligned}
& E_{g}=\sum_{i=1}^{N_{s}} \rho_{i} e_{i}+\frac{1}{2} \rho_{g} u_{g}{ }^{2} \\
& H_{g}=\sum_{i=1}^{N_{s}} \rho_{i} h_{i}+\frac{1}{2} \rho_{g} u_{g}{ }^{2} \\
& p=\left(\sum_{i=1}^{N_{s}} \rho_{i} \bar{R}_{i}\right) T=\rho_{g} \bar{R}_{g} T \\
& \rho_{g}=\sum_{i=1}^{N_{s}} \rho_{i}
\end{aligned}
$$

The individual terms in Eq.(1) are interpreted as follows: rate of storage of total internal energy, net rate of total enthalpy convected by gas flow, net rate of thermal conductive heat flux, and convection rate of total internal energy due to coordinate system movement. The conductivity of pyrolysis gas is much smaller than that of the solid, and thus the conductive heat flux through the gas is ignored. If the internal energy, $\rho_{i} e_{i}$, and the kinetic energy, $\frac{1}{2} \rho_{g} u_{g}{ }^{2}$, of gas flow are ignored, then Eq.(1) reduces to the same form used in the previous work. ${ }^{1}$

Darcy's law is applicable to low speed flows, such as the modeling of underground flows. Typically this means that the Reynolds number, based on the average pore diameter, has an order of magnitude near unity or less.

$$
\operatorname{Re}_{d}=\frac{\rho_{g} u_{g} d_{p}}{\mu_{g}}=O(1)
$$

Darcy's law only accounts for the viscous resistance of the flow. As the flow velocity is increased, inertial terms also should be considered. The Darcy-Forchheimer equation is widely used to account for the inertial effects. The transient Darcy-Forchheimer equation adopted in this work to predict the pyrolysis gas flow velocity is written as

$$
\frac{\partial \varepsilon \rho_{g} \vec{u}_{g}}{\partial t}+\nabla \cdot\left(\varepsilon \rho_{g} \vec{u}_{g} \vec{u}_{g}+\varepsilon \vec{p}\right)=-\varepsilon \frac{\mu_{g}}{K} \vec{u}_{g}-\varepsilon \frac{C_{F}}{\sqrt{K}} \rho_{g}\left|\vec{u}_{g}\right| \vec{u}_{g}+\vec{v} \cdot \nabla \varepsilon \rho_{g} \vec{u}_{g}
$$

where the first term on the right hand side is the Darcy term and the second term is Forchheimer's term, and $K$ and $C_{F}$ are the permeability and the Forchheimer coefficient, respectively. The third term accounts for grid motion in the numerical solution. The left hand side of Eq.(2) is the unsteady form of the Euler equation with porosity.

Most TPS materials are non-isotropic, and therefore the quantities $\mathrm{k}$ and $\mathrm{K}$ actually are tensors. However, in one dimension, we may use the scalar quantities as written in Equations (1) and (2). More general forms that include tensor material properties and also Brinkman's term may be required for solutions in two or three dimensions.

The permeability and the Forchheimer coefficient for both virgin and char must be defined to perform a simulation. Some models and data for permeability and Forchheimer coefficient are available. If the pressure is not too high, the effective permeability may be expressed in the Klinkenberg form as

$$
K=K_{0}\left(1+\frac{b}{P}\right)
$$

where $K_{0}$ is the gas permeability in the limit of continuum flow, and $b$ is a permeability slip parameter that accounts for rarefied flow effects. Values of $K_{0}$ and $b$ for the through-the-thickness direction of PICA are found in the work of Marschall and Cox. ${ }^{13}$ The formula for the Forchheimer coefficient used by Ward ${ }^{14}$ and Ahn et al. ${ }^{6}$ is adopted.

The pyrolysis gas is assumed to have $\mathrm{N}_{\mathrm{s}}$ components. The mass conservation for each component is,

$$
\frac{\partial \varepsilon \rho_{i}}{\partial t}+\nabla \cdot\left(\varepsilon \rho_{i} \vec{u}_{g}+\varepsilon \rho_{g} D_{i} \nabla\left(\frac{\rho_{i}}{\rho_{g}}\right)\right)=\varepsilon \dot{R}_{i}+\dot{R}_{d i}+\vec{v} \cdot \nabla \varepsilon \rho_{i}
$$

and, the global mass conservation is, 


$$
\frac{\partial \varepsilon \rho_{g}}{\partial t}+\nabla \cdot\left(\varepsilon \rho_{g} \vec{u}_{g}\right)=\sum_{i=1}^{N_{s}} \dot{R}_{d i}+\vec{v} \cdot \nabla \varepsilon \rho_{g}
$$

Here $\dot{R}_{d i}$ is the mass generation rate of gas species $i$ due to resin decomposition, and $\dot{R}_{i}$ is the gas species $i$ production rate due to homogenous gas reactions.

For pyrolyzing TPS materials, a standard three-component decomposition model is used. The instantaneous local density of the composite is given by

$$
\rho=\Gamma\left(\rho_{A}+\rho_{B}\right)+(1-\Gamma) \rho_{C}
$$

where the parameter $\Gamma$ is the volume fraction of resin and is an input quantity. The three components decompose independently following the Arrhenius type relation

$$
\frac{\partial \rho_{i}}{\partial t}=-B_{a i} \exp \left(\frac{-E_{a i}}{R T}\right) \rho_{o i}\left(\frac{\rho_{i}-\rho_{r i}}{\rho_{o i}}\right)^{\Psi_{i}}+v \cdot \nabla \rho_{i}
$$

where $\rho_{r i}$ is the residual or terminal density of component $i$, and $\rho_{o i}$ is the original density of component $i . B_{a}, E_{a}$, and $\Psi$ are determined using curve fitting of thermogravimetric analysis data. The mass generation rate of each gas phase chemical species, $\dot{R}_{d i}$, formed during the resin decomposition can be estimated by multiplying the mass production rate computed in Eq.(7) by the mass fraction of each individual chemical species. If the resin decomposition process is under the chemical equilibrium condition, the mass fractions of chemical species can be computed using a chemical equilibrium solver, such as the Aerotherm Chemical Equilibrium (ACE) ${ }^{15}$ or Multicomponent Ablation Thermochemistry (MAT) ${ }^{16}$ codes. If the decomposition process is not in chemical equilibrium, the detail of heterogeneous chemical reactions and their associated rates involved in the decomposition process are required to estimate the mass fraction of each chemical species. For the parametric studies presented in this work, the resin decomposition process is assumed to be under the chemical equilibrium condition. The mass fractions of chemical species formed during the resin decomposition are pre-determined and then arranged in tabular form as one of the FIAT input files.

For a general homogenous chemical reaction, the mass production rate, $\dot{R}_{i}$, of gas species $i$ has the following form:

$$
\dot{R}_{i}=M_{i} \sum_{j=1}^{m}\left(p_{i j}-r_{i j}\right)\left(k_{f j} \prod_{i=1}^{N_{s}}\left(c_{i}\right)^{p_{i}^{\prime}}-k_{r j} \prod_{i=1}^{N_{s}}\left(c_{i}\right)^{r_{i}^{\prime}}\right)
$$

where, $p_{i j}$ and $r_{i j}$ denote the stoichiometric coefficients of species $i$ as a product and a reactant of reaction $j$; $m$ is the total number of reactions and $N_{s}$ is the total number of species; $M_{i}$ is the molecular mass; $k_{f j}$ and $k_{r j}$ are the forward and backward reaction rates; $c_{i}$ is the species concentration; $p_{i}^{\prime}$ and $r_{i}^{\prime}$ are the orders of reaction with respect to species $i$.

A complete set of homogeneous pyrolysis gas chemistry for PICA is not possible at this time, because the reactions and their rates of the pyrolysis flow have not been well studied. The only pyrolysis gas chemistry that was found in the open literature is the work done by April et al. ${ }^{4}$ Because no other choice was available, in this work we adopt April's gas chemistry, and we also assume that the pyrolysis gas formed in the PICA char layer consists of 9 gas species, specifically $\mathrm{H}_{2}, \mathrm{CH}_{4}, \mathrm{CO}, \mathrm{C}_{2} \mathrm{H}_{6}, \mathrm{C}_{2} \mathrm{H}_{4}, \mathrm{C}_{2} \mathrm{H}_{2}, \mathrm{CO}_{2}, \mathrm{H}_{2} \mathrm{O}$, and $\mathrm{C}$, which are the most abundant species for some chemical equilibrium conditions. The eight chemical reactions considered in this work and their rates are listed in Table I. A detail discussion of these reactions is presented in the papers by April et al. 
Table I: List of pyrolysis gas chemical reactions and rates

\begin{tabular}{|c|c|c|c|c|c|}
\hline $\begin{array}{l}\text { Reaction } \\
\text { number }\end{array}$ & Reaction Formula & Rate Law & E(Kcal/g-mole) & A & $\mathrm{s}$ \\
\hline 1 & $2 \mathrm{CH}_{4} \leftrightarrow \mathrm{C}_{2} \mathrm{H}_{6}+\mathrm{H}_{2}$ & $k_{f}\left[\mathrm{CH}_{4}\right]$ & 95 & $7.6 \times 10^{14}$ & 0 \\
\hline 2 & $\mathrm{C}_{2} \mathrm{H}_{6} \leftrightarrow \mathrm{C}_{2} \mathrm{H}_{4}+\mathrm{H}_{2}$ & $k_{f}\left[\mathrm{C}_{2} \mathrm{H}_{6}\right]$ & 70 & $3.1 \times 10^{14}$ & 0 \\
\hline 3 & $\mathrm{C}_{2} \mathrm{H}_{4} \leftrightarrow \mathrm{C}_{2} \mathrm{H}_{2}+\mathrm{H}_{2}$ & $k_{f}\left[\mathrm{C}_{2} \mathrm{H}_{4}\right]$ & 40 & $2.6 \times 10^{8}$ & 0 \\
\hline 4 & $\mathrm{C}_{2} \mathrm{H}_{2} \leftrightarrow 2 \mathrm{C}+\mathrm{H}_{2}$ & $k_{f}\left[\mathrm{C}_{2} \mathrm{H}_{2}\right]^{2}$ & 10 & $2.1 \times 10^{10}$ & 0 \\
\hline 5 & $\mathrm{C}+2 \mathrm{H}_{2} \leftrightarrow \mathrm{CH}_{4}$ & $k_{f}$ & 17 & $2.0 \times 10^{9}$ & 0 \\
\hline 6 & $\mathrm{C}+\mathrm{H}_{2} \mathrm{O} \leftrightarrow \mathrm{CO}+\mathrm{H}_{2}$ & $k_{f}[\mathrm{C}]\left[\mathrm{H}_{2} \mathrm{O}\right]$ & 82 & $1.2 \times 10^{12}$ & -1 \\
\hline 7 & $\mathrm{CO}+\mathrm{H}_{2} \mathrm{O} \leftrightarrow \mathrm{H}_{2}+\mathrm{CO}_{2}$ & $k_{f}[\mathrm{CO}]\left[\mathrm{H}_{2} \mathrm{O}\right]$ & 30 & $1.0 \times 10^{12}$ & 0 \\
\hline \multirow[t]{2}{*}{8} & $\mathrm{C}+\mathrm{CO}_{2} \leftrightarrow 2 \mathrm{CO}$ & $k_{f}[\mathrm{C}]-k_{r}[\mathrm{CO}]$ & 50 & $1.0 \times 10^{6}$ & $\overline{-1}$ \\
\hline & & & 61 & $1.0 \times 10^{-9}$ & 0 \\
\hline
\end{tabular}

The specific heat of solid is input as a function of temperature for both virgin and fully-charred material. In partially pyrolyzed zones $\left(\rho_{c}<\rho<\rho_{v}\right)$, the specific heat is obtained from the mixing rule

$$
c_{p}=\tau c_{p v}+(1-\tau) c_{p c}
$$

where

$$
\tau=\frac{\rho_{v}}{\rho_{v}-\rho_{c}}\left(1-\frac{\rho_{c}}{\rho}\right)
$$

The weighting variable $\tau$ is the mass fraction of virgin material, in a hypothetical mixture of virgin material and char, which yields the correct local density. The thermal conductivity, $k$, is weighted in a similar manner as $c_{p}$.

\section{Boundary Conditions}

Conditions at the ablating surface are determined by convective and radiative heating and by surface thermochemical interactions with boundary-layer gases. The surface energy balance equation is written in general convective transfer-coefficient form as follows:

$$
\rho_{e} u_{e} C_{H}\left(H_{r}-h_{w}\right)+\dot{m}_{c}\left(h_{c}-h_{w}\right)+\dot{m}_{g}\left(h_{g}-h_{w}\right)+\alpha_{w} q_{r w}-\sigma \varepsilon_{w}\left(T_{w}^{4}-T_{\infty}^{4}\right)-q_{c w}=0
$$

The first term in Eq. (12) represents the sensible convective heat flux. The sum of the second, and third terms in Eq. (12) is defined as the total chemical energy at the surface. The fourth and fifth terms are the radiative heat fluxes absorbed and re-radiated by the wall, respectively, and the last term, $q_{c w}$, represents the rate of heat conduction into the TPS. If the surface is at the chemical equilibrium condition, ACE and MAT codes can be used to generate tables of normalized mass blowing rate, $B_{c}^{\prime}\left(=\frac{\dot{m}_{c}}{\rho_{e} u_{e} C_{M}}\right)$. For a chemical non-equilibrium surface, the char recession rate, $\dot{m}_{c}$, can be computed through coupling FIAT and a Computational Fluid Dynamics code with finite-rate surface chemistry capability, such as DPLR ${ }^{17}$. The enhanced version of FIAT code can read either the $B^{\prime}$ tables or the char recession rates, $\dot{m}_{c}$.

A blowing correction accounts for the reduction in transfer coefficients due to the transpiration of gases from pyrolysis and surface ablation into the boundary layer. The blowing rate correction equation for convective heat transfer is 


$$
\frac{C_{H}}{C_{H 1}}=\frac{\ln \left(1+2 \lambda B^{\prime}\right)}{2 \lambda B^{\prime}}
$$

where $\lambda$ is the blowing reduction parameter, $C_{H}$ is the heat transfer coefficient for the ablating surface, and $C_{H 1}$ is the heat transfer coefficient for the non-ablating surface. With $\lambda=0.50$, Eq. (13) reduces to the classical blowing correction for laminar flow. ${ }^{18}$

\section{Test Cases}

The computations presented in this section focus on the in-depth thermal response of PICA heat-shield material. The first group of simulations is based on a lunar return trajectory for Orion, and the second group uses a representative variety of stream conditions for CEV TPS ADP arc-jet testing conducted at NASA Ames Research Center. The effects of gas momentum transfer and pyrolysis gas homogeneous reactions on PICA in-depth thermal response are examined. In each group, we first solve the Darcy-Forchheimer momentum equation under the assumption of chemical equilibrium to understand how the inclusion of gas momentum transfer and gas kinetic energy affects the in-depth temperature prediction. Then, the gas momentum equation is solved with finite-rate homogenous reactions, developed by April for pyrolysis gas flow, to study how the gas phase chemistry influences the PICA material thermal response. For each group, the predictions of PICA material thermal response using ninespecies finite-rate gas chemistry, equilibrium gas chemistry, and frozen gas chemistry are presented and compared with those using the baseline FIAT/PICA model developed for CEV TPS ADP.

\section{A. Group I}

The aerothermal environment for the first group is shown in Fig. 1. This flight environment is a dual convective heat pulse based on a proposed lunar return trajectory for Orion. The first peak convective heat flux is $245 \mathrm{~W} / \mathrm{cm}^{2}$ at $105 \mathrm{sec}$, and the second peak is $85 \mathrm{~W} / \mathrm{cm}^{2}$ at $523 \mathrm{sec}$. The radiative heat flux is a single pulse with a maximum of $204 \mathrm{~W} / \mathrm{cm}^{2}$ at $80 \mathrm{sec}$.

The black lines shown in Fig. 2 are the PICA in-depth temperature histories at various depths (surface, $0.24 \mathrm{~cm}$, $0.51 \mathrm{~cm}, 1.15 \mathrm{~cm}, 1.76 \mathrm{~cm}, 3.81 \mathrm{~cm}$, and $5.08 \mathrm{~cm}$ ) predicted by the regular version of FIAT using the baseline thermal response model, PICAv3.3, developed for CEV TPS ADP. The red lines are predictions of the enhanced version of FIAT which solves the Darcy-Forchheimer momentum equation and the global mass conservation equation with, in this case, the assumption of chemical equilibrium for the pyrolysis gas flow. Both predictions are performed using a baseline 119-species pyrolysis gas model. In general, the enhanced version predicts slightly lower in-depth temperature than the regular version for locations inside the char and pyrolysis zones. At depths of $3.81 \mathrm{~cm}$ and $5.08 \mathrm{~cm}$, at which the temperature is not sufficiently high for pyrolysis to be significant, the difference between these two predictions is very small. The consideration of gas momentum equation does not appear to have significant impact on the thermal response prediction. The difference on temperature prediction is mainly driven by the introduction of kinetic energy of pyrolysis gas in the total energy balance equation (Eq. 1). The gas kinetic energy is not considered in the energy balance terms of regular version of FIAT. One can conclude that the kinetic energy of pyrolysis gas is a relatively small component in the global energy balance of PICA material, and thus the difference in predicted temperatures between two simulations is small. Ignoring the kinetic energy of pyrolysis gas should not have significant impact on the accuracy of PICA material thermal response predictions. However, in a material thermal response model with finite-rate gas chemistry, an accurate prediction of the gas flow rate is required for the computation of chemical species concentrations.

The pyrolysis gas mass injection rate vs. time is presented in Fig. 3. The prediction from the regular version of FIAT (in red) is just slightly higher than that from the enhanced version (in black). Instead of solving the gas momentum conservation equation and each individual gas species mass conservation equation, the regular version of FIAT code assumes that all the pyrolysis gas flows outward with neither resistance nor accumulation, and thus the gas flow rate can be obtained by simply solving the global gas mass conservation equation. Based on the results of current analysis, this assumption is proved to be reasonable for the flight conditions considered here.

To examine the effect of variation of permeability on PICA in-depth thermal response, computations with various values of permeability are performed. The results presented are for the permeabilities equal to baseline value $(\mathrm{K})$, twice of baseline $(2 \mathrm{~K})$, and half of baseline $(0.5 \mathrm{~K})$. Figures $4 \mathrm{a}$ and $4 \mathrm{~b}$ show the in-depth temperature and gas pressure profiles at $80 \mathrm{sec}$, the first peak of surface temperature, and, at $515 \mathrm{sec}$, the second peak of surface temperature, respectively. The temperature distributions are almost unaffected by the variation of permeability. The maximum temperature difference due to the variation of permeability is $20^{\circ} \mathrm{K}$ which is too small to be seen in this plot. Thus, only the temperature distribution for baseline permeability is shown in this chart. The increase of 
pyrolysis gas pressure is about 15 to $20 \%$, as the permeability is reduced by $50 \%$, and conversely the pyrolysis gas pressure decreases if the permeability increases. The predicted pyrolysis gas density and solid density are plotted in Figs. $5 \mathrm{a}$ and $5 \mathrm{~b}$ for the same time steps ( 80 and $515 \mathrm{sec}$ ). The effect of variation of permeability on gas density is similar to that on gas pressure. In Figures $6 \mathrm{a}$ and $6 \mathrm{~b}$, the gas kinetic energy density and pyrolysis mass flow rate at time equal to $80 \mathrm{sec}$ and $515 \mathrm{sec}$ are presented. As expected, flow speed and kinetic energy increase as the value of permeability increases. The total pyrolysis mass flow rate, which mostly depends on the resin decomposition rate, is not sensitive to the variation of permeability.

The selection of chemical species is limited by the availability of an applicable finite-rate gas chemistry model. To better estimate the uncertainty associated with using a simple nine-species gas chemistry for predicting of PICA material in-depth thermal response, a corresponding nine-species chemical equilibrium gas chemistry model was used. Both the equilibrium and the finite-rate models contain exactly the same nine chemical species. In Figure 7a, the comparison of FIAT predictions between the baseline 119-species equilibrium chemistry model (in black), which is used in the regular version of FIAT/PICA model, and the simple 9-species equilibrium chemistry model (in blue) is presented. The difference on predicted in-depth temperature profiles between the 9-species and 119-species chemical equilibrium models is fairly small, except that at depths of $1.15 \mathrm{~cm}$ and $1.76 \mathrm{~cm}$, where the 9-species predictions are lower than those of 119-species predictions. This discrepancy is mainly due to differences in the gas enthalpy inside the pyrolysis zone. The difference on predicted in-depth temperature between these two equilibrium chemistry models is considered to be acceptable for the purpose of this parametric study. Since there is no other finite-rate gas chemistry model available, we have to accept the errors which may be generated as the result of using a simple nine-species model for the parametric studies performed in this section. The number of gas phase chemical species should be increased in a future study, when a more robust finite-rate homogenous reaction model becomes available.

Figure 7b presents the in-depth temperature profiles for the finite-rate (black lines), frozen (red lines), and equilibrium (blue lines) models with nine chemical species. The frozen chemistry solutions are obtained by turning off all the reactions in the finite-rate model. The greatest difference among these three models occurs at depth of $1.76 \mathrm{~cm}$. Generally speaking, the frozen chemistry has the highest temperature predictions, and the equilibrium chemistry has the lowest. This discrepancy is certainly due to the difference on the gas phase chemical reaction rates in each model.

A comparison of temperature profiles between the nine-species finite-rate chemistry model (black lines) and the regular FIAT model (red lines) is presented in Fig. 7c. The overall difference between these two predictions is not insignificant. At depths of $0.24 \mathrm{~cm}$, and $0.51 \mathrm{~cm}$, where PICA is fully charred most of the time, the regular FIAT model predicts slightly lower temperature as compared with the nine-species finite-rate FIAT, due to the difference in accounting for gas kinetic energy. At deeper locations, including $1.76 \mathrm{~cm}, 3.81 \mathrm{~cm}$, and $5.08 \mathrm{~cm}$, the kinetic energy term is less important. The gas enthalpy is the main difference between these two models, and thus the temperature predictions of the nine-species finite-rate model are slightly higher than those of the regular version.

Figures $8 \mathrm{a}$ and $8 \mathrm{~b}$ compare the mass concentrations for $\mathrm{CO}_{2}, \mathrm{C}_{2} \mathrm{H}_{2}, \mathrm{CH}_{4}, \mathrm{H}_{2}$, and $\mathrm{CO}$ predicted by the finite-rate (solid lines) and equilibrium (dashed lines) gas chemistry models at $80 \mathrm{sec}$ and $515 \mathrm{sec}$, respectively. The mass fractions for the other 4 species are not presented because of their relatively low concentrations. The pyrolysis gas flow is first produced inside the pyrolysis zone, expands into the char zone, reaches the front face, and then mixes with the flow surrounding the TPS system. For a chemical equilibrium model, the local chemical species concentrations depend on local temperature and pressure. However, for a finite-rate model, the individual chemical species concentration is driven by the production rate of each individual species, which is a time-dependent process. The history of local species concentrations, temperature, pressure, and flow speed all affect the extent to which the finite-rate chemistry model approaches a chemical equilibrium condition. At time equal to $80 \mathrm{sec}$, the finite-rate model prediction gradually approaches chemical equilibrium as the pyrolysis gas flow moves near the front surface. Nonetheless, in this same region, at time equal to $515 \mathrm{sec}$, the species concentrations predicted using the finite-rate model still have not reached those predicted using the chemical equilibrium model, because of relatively low gas density and pressure. We note here again that this finite-rate model excludes heterogeneous reactions that may be important and which could increase the rate at which pyrolysis gas chemistry approaches equilibrium conditions.

\section{B. Group II}

Figure 9 shows three representative arcjet heating environments for the second group of FIAT simulations. The first case has surface heat flux of $900 \mathrm{~W} / \mathrm{cm}^{2}$, pressure of $64 \mathrm{kPa}$, and exposure duration of $30 \mathrm{sec}$. The second case has surface heat flux of $600 \mathrm{~W} / \mathrm{cm}^{2}$, pressure of $26 \mathrm{kPa}$, and exposure duration of $50 \mathrm{sec}$. The third case has surface heat flux of $200 \mathrm{~W} / \mathrm{cm}^{2}$, pressure of $7 \mathrm{kPa}$, and exposure duration of $100 \mathrm{sec}$. The computations performed in this group are similar to those in the Group I. 
Figures 10a to 10c present temperature histories at various depths (surface, $0.24 \mathrm{~cm}, 0.51 \mathrm{~cm}, 1.15 \mathrm{~cm}, 1.76 \mathrm{~cm}$, $3.81 \mathrm{~cm}$, and $5.08 \mathrm{~cm}$ ) computed by the regular version of FIAT (red lines) and the enhanced version of FIAT (black lines) using the baseline 119-species equilibrium chemistry model for all three arc-jet simulation cases. The results again indicate that consideration of gas momentum transfer and gas kinetic energy only slightly decreases the predicted in-depth temperature. This result is obtained because the kinetic energy of pyrolysis gas is relatively small compared with other components of internal energy.

The effect of permeability variations on gas pressure, density, and kinetic energy are also studied in this group. In Figs 11a to 11c, the gas temperature and pressure profiles at the end of each heat pulse for three permeability levels $(0.5 \mathrm{~K}, \mathrm{~K}$, and $2 \mathrm{~K})$ are presented. The gas density and solid density distributions at the end of heat pulse are given in Figs 12a to 12c, and the distributions of kinetic energy density and mass flow rate are shown in Figs 13a to 13c. An increase of permeability reduces gas pressure and density; however, it increases gas flow speed and kinetic energy. These predictions confirm that gas mass flow rate and temperature are not particularly sensitive to the variation of permeability for PICA.

A comparison of predicted temperature histories for the nine-species finite-rate (black lines), frozen (red lines), and equilibrium (blue lines) gas chemistry models is provided in Figs 14a to 14c for the three arc-jet conditions. The observed discrepancy on the PICA in-depth temperature predictions among three chemistry models mainly results from the gas phase enthalpy. This is because the predicted chemical species concentrations strongly depend on the chemistry model implemented in the code, and the gas enthalpy is a function of chemical species concentrations. Inside the pyrolysis zone, the maximum difference on predicted in-depth temperature is $40{ }^{\circ} \mathrm{K}$. For this arc-jet group, the effect of uncertainty on gas phase chemistry modeling of pyrolysis gas appears to have less influence on the overall PICA thermal response as compared with the first group of flight simulations, because of the relatively thin char layer.

Figures 15a to 15c show the predicted mass fractions of $\mathrm{CO}_{2}, \mathrm{C}_{2} \mathrm{H}_{2}, \mathrm{CH}_{4}, \mathrm{H}_{2}$, and $\mathrm{CO}$ for nine-species finite-rate (solid lines) and nine-species equilibrium (dashed lines) chemistry models at the end of each heat pulse. The trends are similar to what was seen in Group I. For all three arcjet conditions, the results of the nine-species finite-rate chemistry model indicate that the pyrolysis gas flow is at or near chemical equilibrium in the region near the front surface of PICA.

\section{Conclusions}

A special version of FIAT was developed. The new capabilities implemented in this version of FIAT include the time-dependent pyrolysis gas flow momentum equation with Darcy-Forchheimer terms and the pyrolysis gas species conservation equations with a nine-species finite-rate homogeneous chemical reaction model developed specifically for the PICA heatshield material. The total energy conservation equation was also enhanced to reflect these additions. Various parametric studies were performed for two groups of test cases. The first group used a heating environment for a proposed Orion lunar return vehicle, and the second group used three heating environments for arc-jet tests conducted at NASA Ames Research Center. The central focus of these parametric studies was to understand the effect of pyrolysis gas chemistry on the in-depth thermal response. Thus finite-rate, equilibrium, and frozen homogenous gas chemistry models for pyrolysis gas were examined.

Results from the current parametric studies show that gas kinetic energy is a relatively small component in the internal energy balance equation, and neglecting gas kinetic energy has little negative impact on the accuracy of indepth temperature predictions. The in-depth temperature predictions using a finite-rate or a frozen pyrolysis gas chemistry model are higher than those using a chemical equilibrium model. The results computed using April's finite-rate gas chemistry model indicate that pyrolysis gas flow is at or near a chemical-equilibrium condition in the region near the front surface of PICA for all flow conditions studied in this work. Compared with the baseline PICA/FIAT model developed by Orion TPS ADP, this enhanced version of FIAT tends to predicting slightly lower temperatures in the char zone due to the effect of pyrolysis gas kinetic energy, and slightly higher temperatures in the pyrolysis zone as the result of finite-rate chemical reactions. However, overall the differences in predicted indepth temperatures are considered to be small. The presence of chemical non-equilibrium pyrolysis gas flow does not significantly alter the PICA in-depth thermal response performance predicted using the chemical equilibrium gas model. Thus the PICA/FIAT material thermal response model developed by Orion TPS ADP should be applicable for a fairly wide range of entry conditions with reasonably good accuracy.

\section{Acknowledgements}

This work was funded by the NASA Fundamental Aeronautics Program Hypersonics Project. 


\section{References}

${ }^{1}$ Chen, Y.-K., and Milos, F.S., "Ablation and Thermal Analysis Program for Spacecraft Heatshield Analysis," Journal of Spacecraft and Rockets, Vol. 36, No. 3, 1999, pp. 475-483.

${ }^{2}$ Chen, Y.-K., and Milos, F.S., "Two-Dimensional Implicit Thermal Response and Ablation Program for

Charring Materials," Journal of Spacecraft and Rockets, Vol. 38, No. 4, 2001, pp. 473-481.

${ }^{3}$ Chen, Y.-K., and Milos, F.S., "Three-Dimensional Ablation and Thermal Response Simulation System," AIAA Paper 2005-5064, June 2005.

${ }^{4}$ April, G.C., Pike, R.W., and Del Valle, E.G., "Modeling Reacting Gas Flow in the Char Layer of an Ablator, " AIAA Journal, Vol. 9, No. 6, June 1971, pp 1113-1119.

${ }^{5}$ Ayasoufi, A., Rahmani, R.K., Cheng, G., Koomullil R., and Neroorkar, K., "Numerical Simulation of Ablation for Reentry Vehicles, " AIAA Paper 2006-2908, June 2006.

${ }^{6}$ Ahn, Hyo-Keun, , Park, Chul, and Sawada, K., "Response of Heatshield Material at Stagnation Point of PioneerVenus Probes, " Journal of Thermophysics and Heat Transfer, Vol. 16, No. 3, July-September 2002, pp 432-439.

${ }^{7}$ Martin A. and Boyd, I.D., "Non-Darcian Behavior of Pyrolysis Gas in a Thermal Protection System, " Journal of Thermophysics and Heat Transfer, Vol. 24, No. 13, January-March 2010, pp 60-68.

${ }^{8}$ Bartlett, E.P., Abbett, M.J., Nicolet, W.E., and Moyer, C.B., "Improved Heat-Shield Design Procedures for Manned Entry Systems", Aerotherm Report No. 70-15, Part II, June 1970.

${ }^{9}$ Knupp, P.M., and Lage, J.L., "Generalization of the Forchheimer-extended Darcy Flow Model to the Tensor Permeability Case via a Variational Principle," J. Fluid Mech. Vol. 299, 1995, pp. 97-104.

${ }^{10}$ Tran, H., Johnson, C, Rasky, D., Hui, F., Chen, Y.-K., and Hsu, M., "Phenolic Impregnated Carbon Ablators (PICA) for Discovery Class Missions," AIAA Paper 96-1911, June 1996.

${ }^{11}$ Willcockson, W. H,. "Stardust Sample Return Capsule Design Experience," Journal of Spacecraft and Rockets, Vol. 36, No. 3, 1999, pp. 470-474.

${ }^{12}$ Milos, F.S., and Chen, Y.-K., "Ablation and Thermal Response Property Model Validation for Phenolic Impregnated Carbon Ablator," Journal of Spacecraft and Rockets, Vol. 47, No. 5, 2010, pp. 786-805.

${ }^{13}$ Marschall, J. and Cox M. E., "Gas Permeability of Lightweight Ceramic Ablators," Journal of Thermophysics and Heat Transfer. Vol. 13, No. 3: Technical Notes, 1999, pp. 382-384.

${ }^{14}$ Ward, J. C., "Turbulent Flow in Porous Media," ASCE, vol. 90, No. HY-5, 1964, pp. 1-12.

${ }^{15}$ Anon., User's Manual: Aerotherm Chemical Equilibrium Computer Program, Acurex Corporation, Aerotherm Division, Mountain View, CA, Aug. 1981.

${ }^{16}$ Milos, F.S., and Chen, Y.-K., "Comprehensive Model for Multi-Component Ablation Thermochemistry," AIAA Paper 97-0141, Jan. 1997.

${ }^{17}$ Wright, M. J., Candler, G. V., and Bose, D., "Data-Parallel Line Relaxation Method for the Navier-Stokes Equations," AIAA Journal, Vol. 36, No. 9, Sept. 1998, pp 1603-1609.

${ }^{18}$ Kays, W.M., and Crawford, M.E., Convective Heat and Mass Transfer, 2nd Edition, McGraw-Hill, 1980, pp. 355-357. 


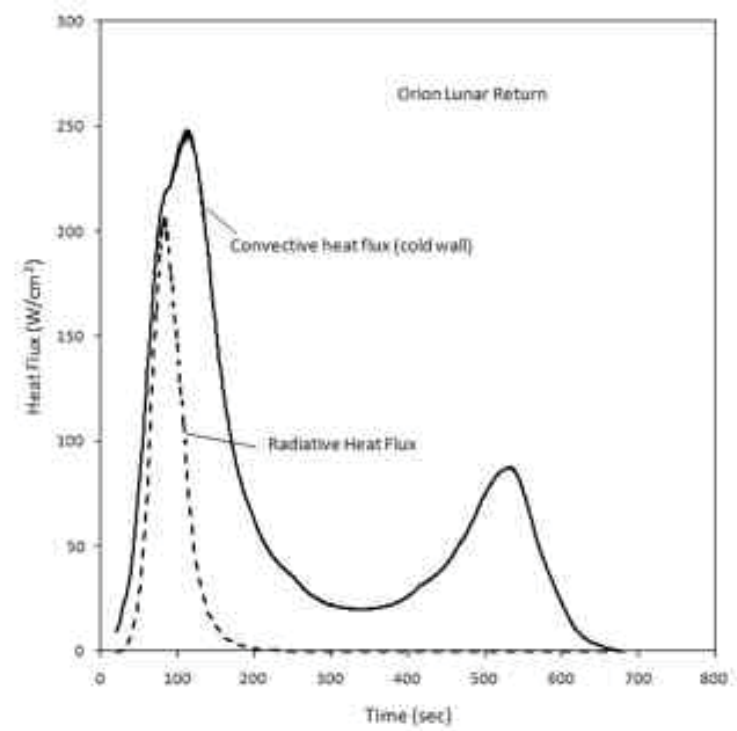

Figure 1: Aerothermal environment for Group I

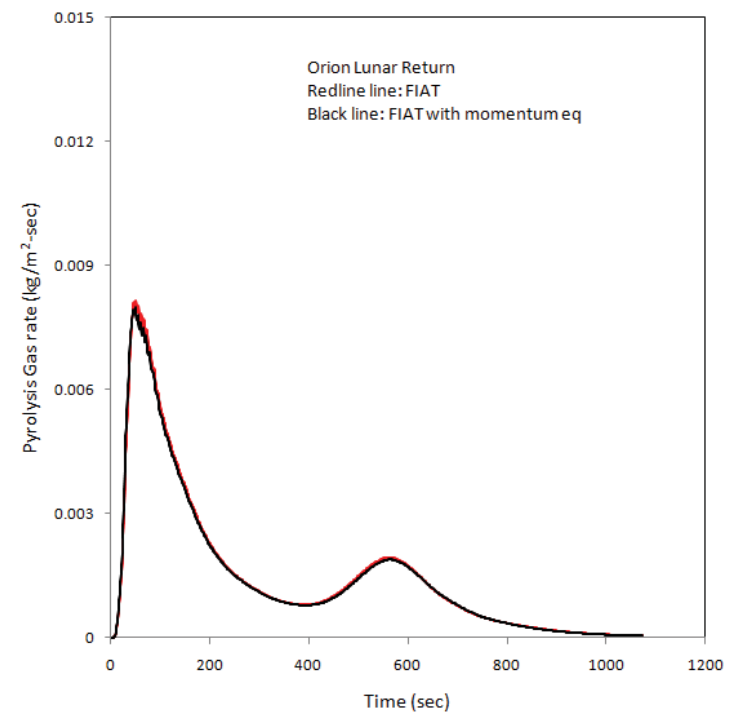

Figure 3: Pyrolysis gas mass injection rate predicted by baseline FIAT and by FIAT with momentum equation.

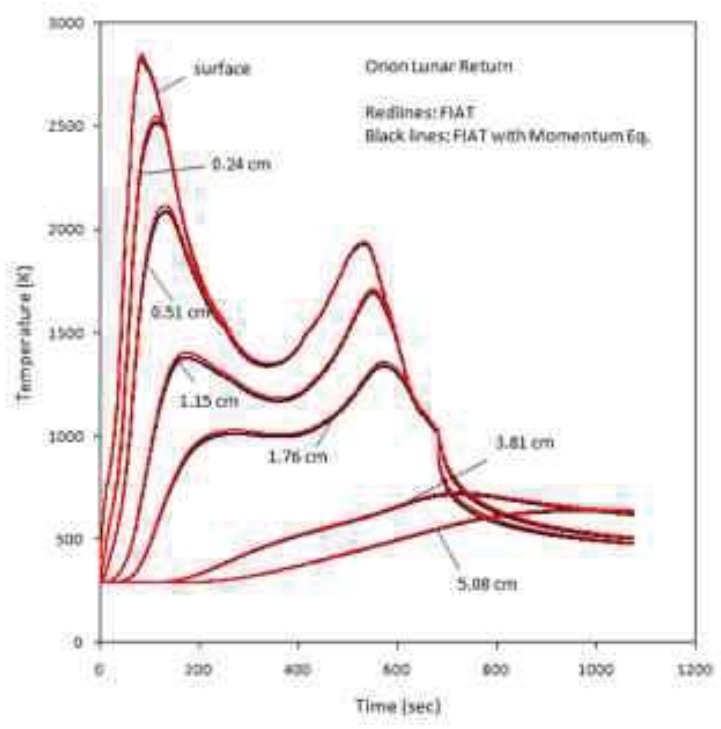

Figure 2: Surface and in-depth temperatures predicted by baseline FIAT and by FIAT with momentum equation.

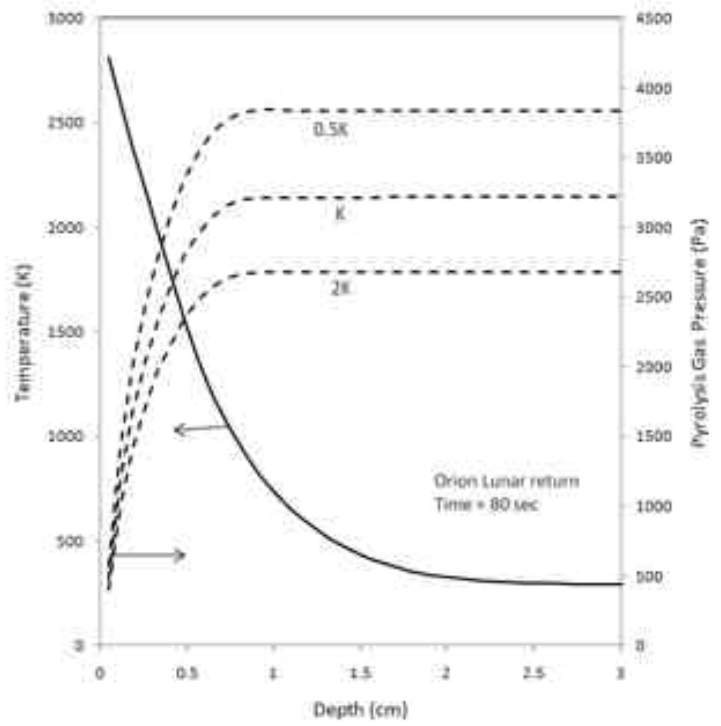

Figure 4a: Temperature and pressure profiles at time equal to $80 \mathrm{sec}$. 


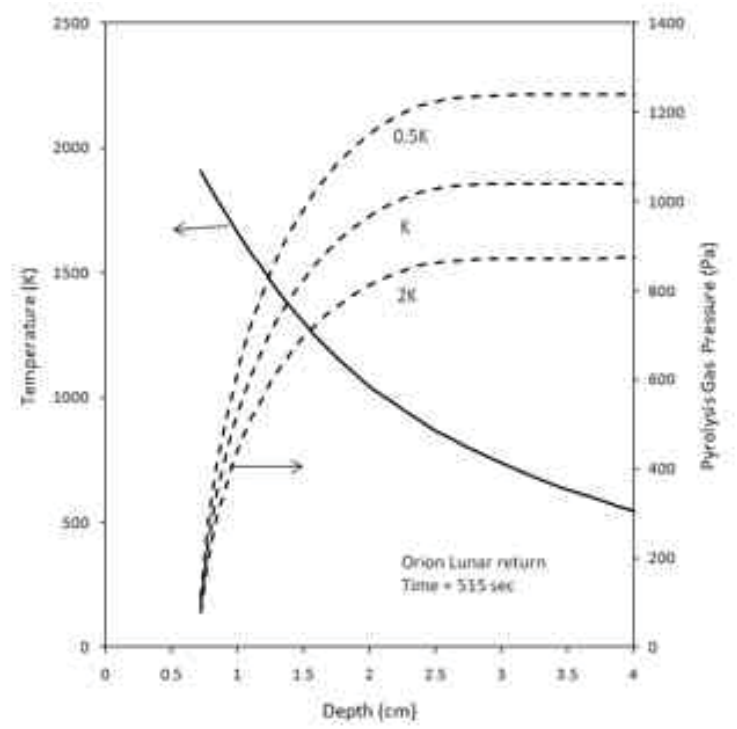

Figure 4b: Temperature and pressure profiles at time equal to $515 \mathrm{sec}$.

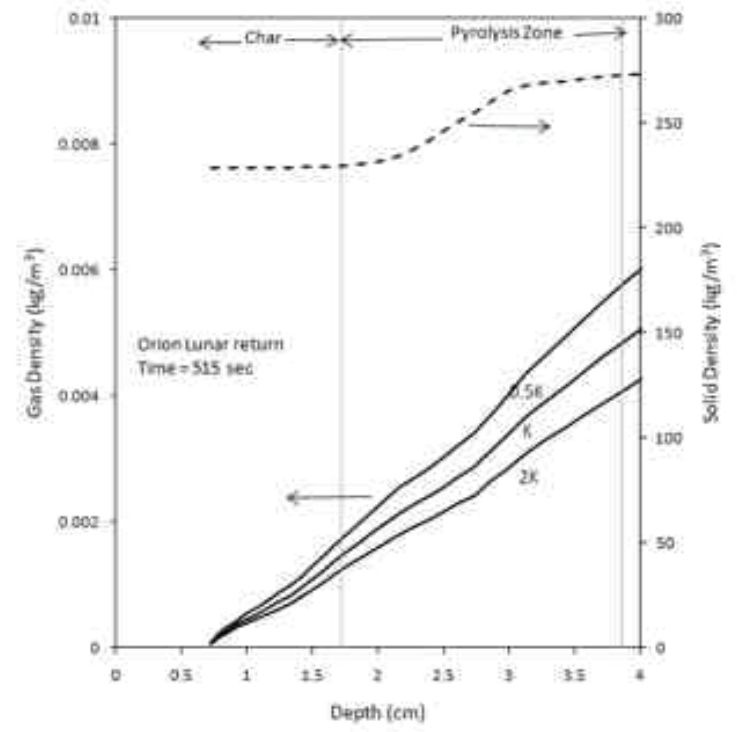

Figure 5b: gas and solid density distributions at time equal to $515 \mathrm{sec}$

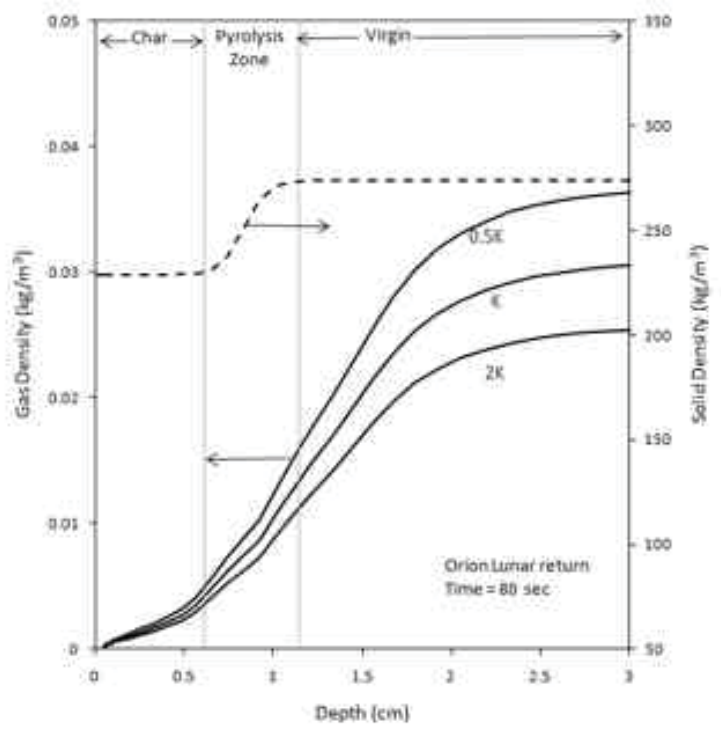

Figure 5a: Gas and solid density distributions at time equal to $80 \mathrm{sec}$

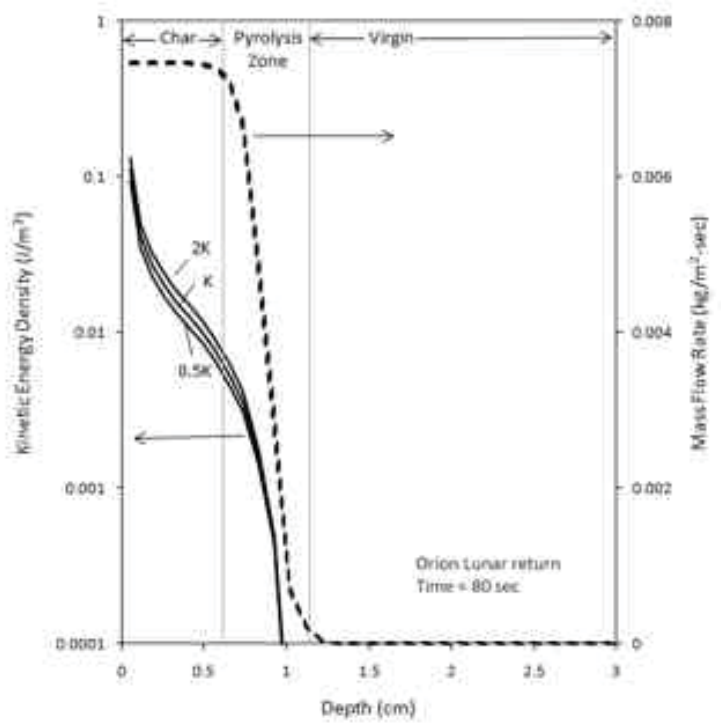

Figure 6a: Kinetic energy density and mass flow rate distributions at time equal to $80 \mathrm{sec}$ 


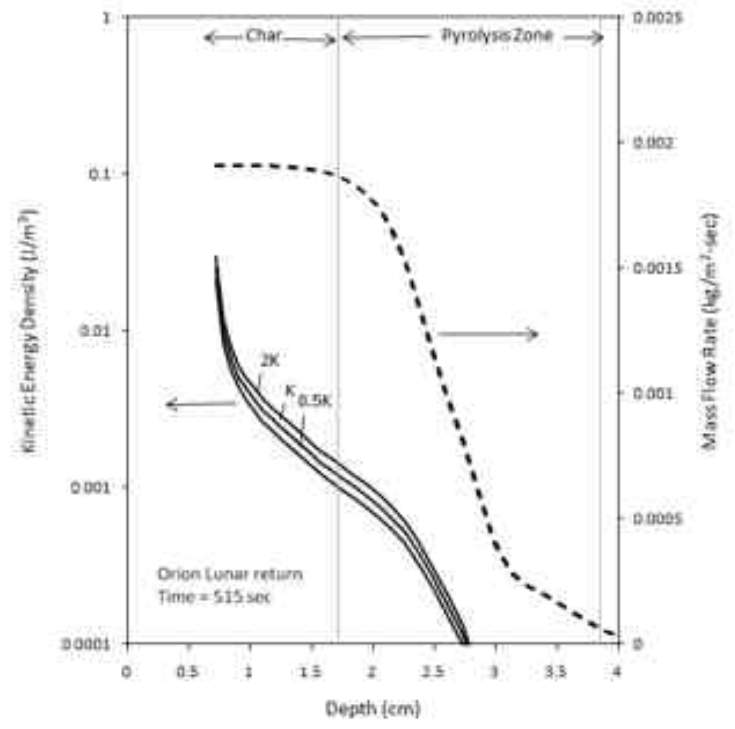

Figure 6b: Kinetic energy density and mass flow rate distributions at time equal to $515 \mathrm{sec}$

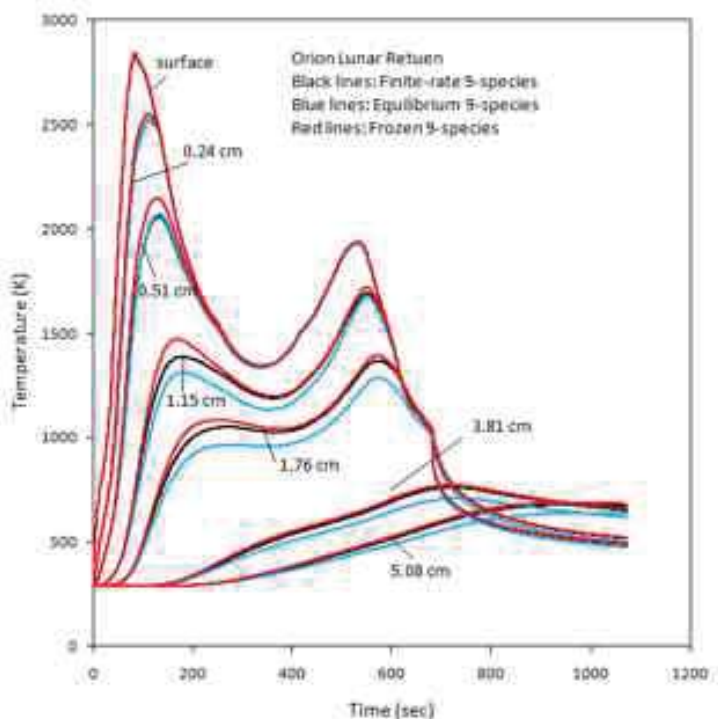

Figure 7b: Surface and in-depth temperatures predicted by finite-rate, equilibrium, and frozen gas chemistry models

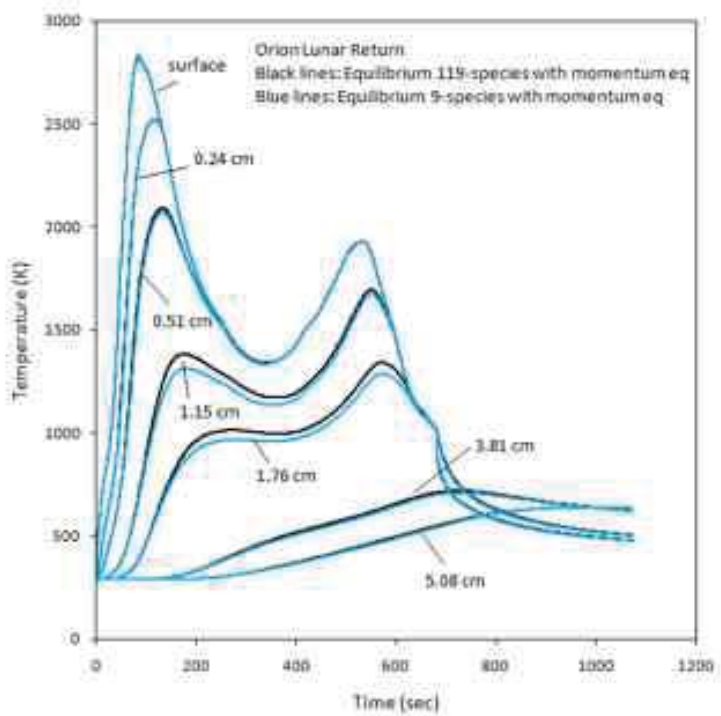

Figure 7a: Surface and in-depth temperatures predicted by 119 -species and 9-species chemical equilibrium models

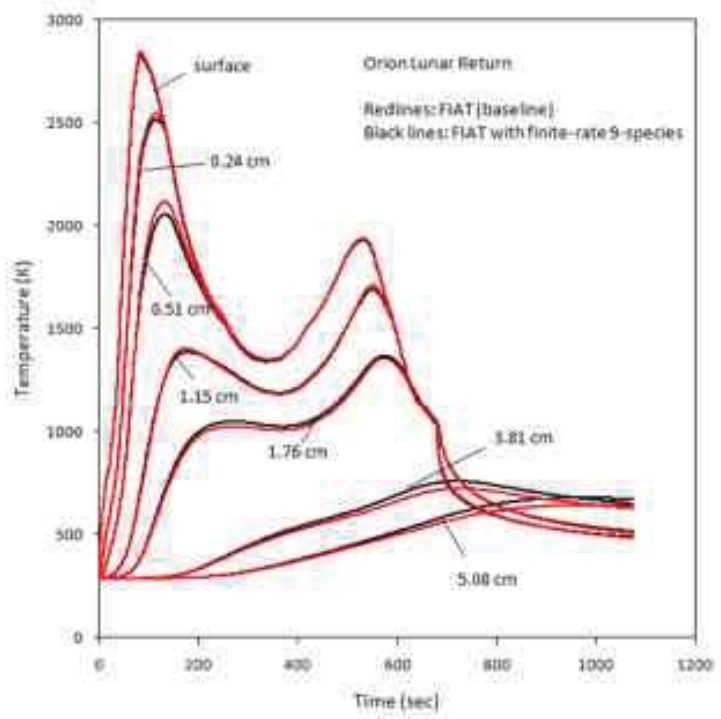

Figure 7c: Surface and in-depth temperatures predicted by baseline FIAT and by enhanced FIAT with 9-species chemistry 


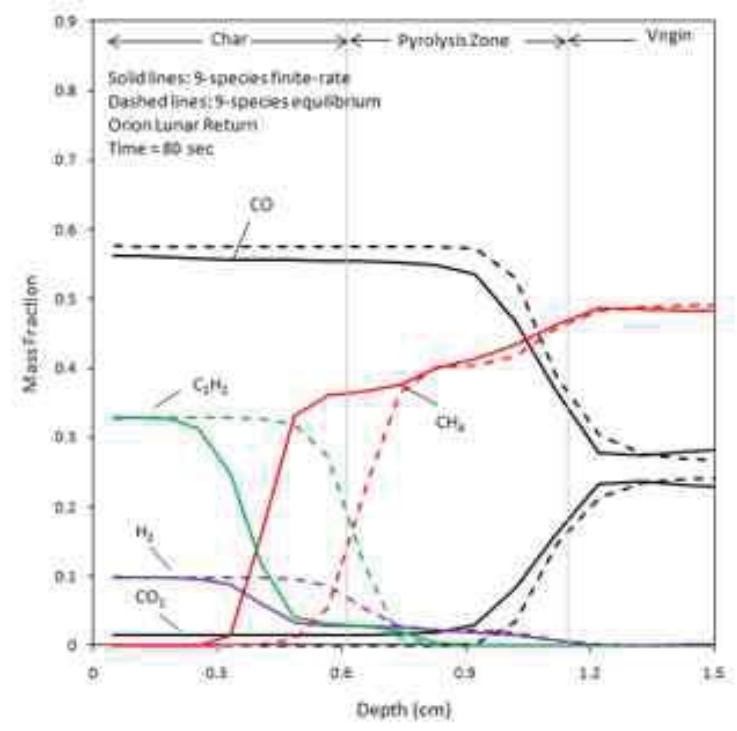

Figure 8a: Mass fraction profiles predicted by finiterate and chemical equilibrium chemistry models at time equal to $80 \mathrm{sec}$

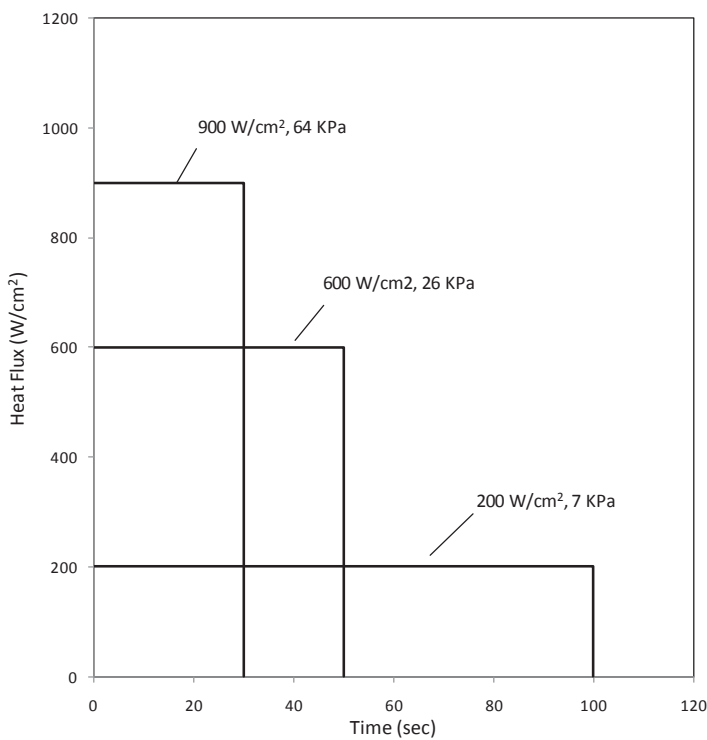

Figure 9: Three arc-jet test conditions for Group II

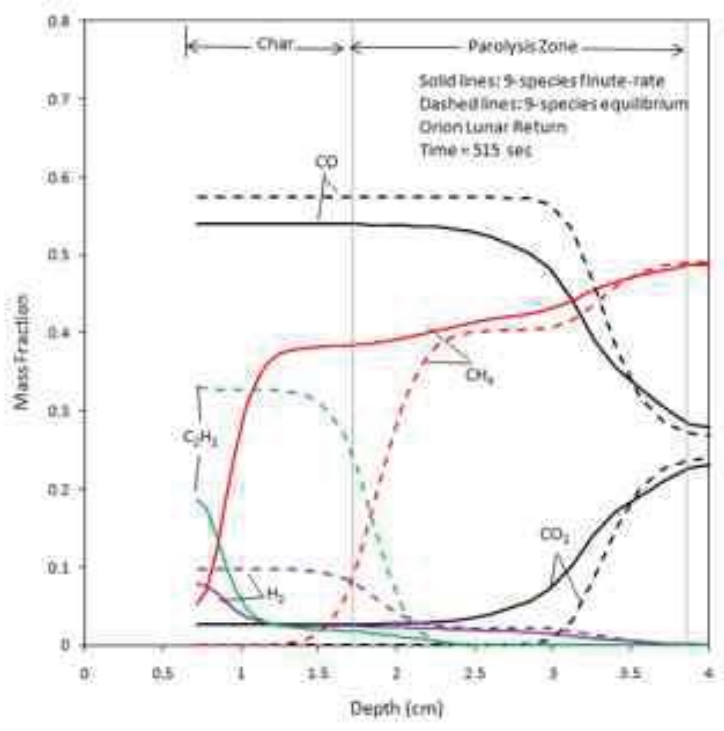

Figure 8b: Mass fraction profiles predicted by finiterate and chemical equilibrium chemistry models at time equal to $515 \mathrm{sec}$

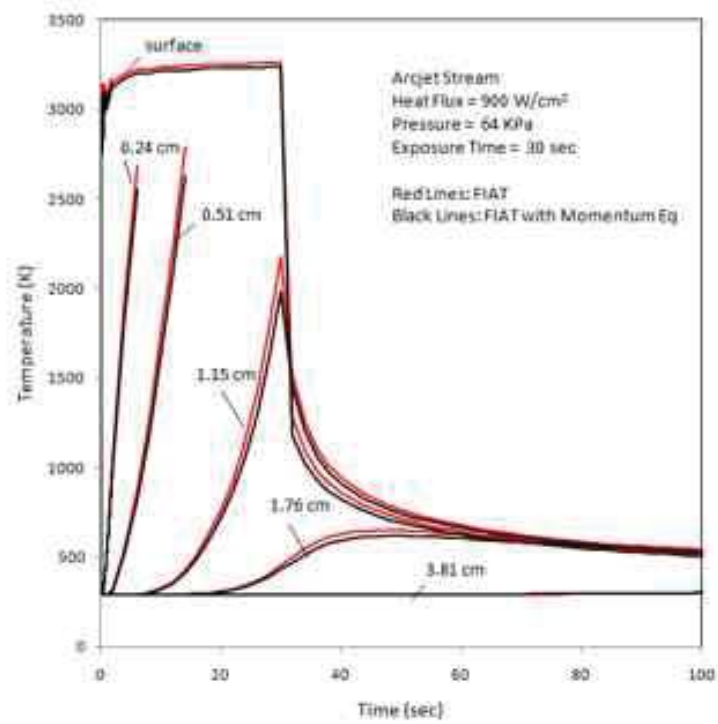

Figure 10a: Surface and in-depth temperatures predicted by baseline FIAT and by enhanced FIAT with chemical equilibrium chemistry for heat flux of $900 \mathrm{~W} / \mathrm{cm}^{2}$ and pressure of $64 \mathrm{kPa}$ 


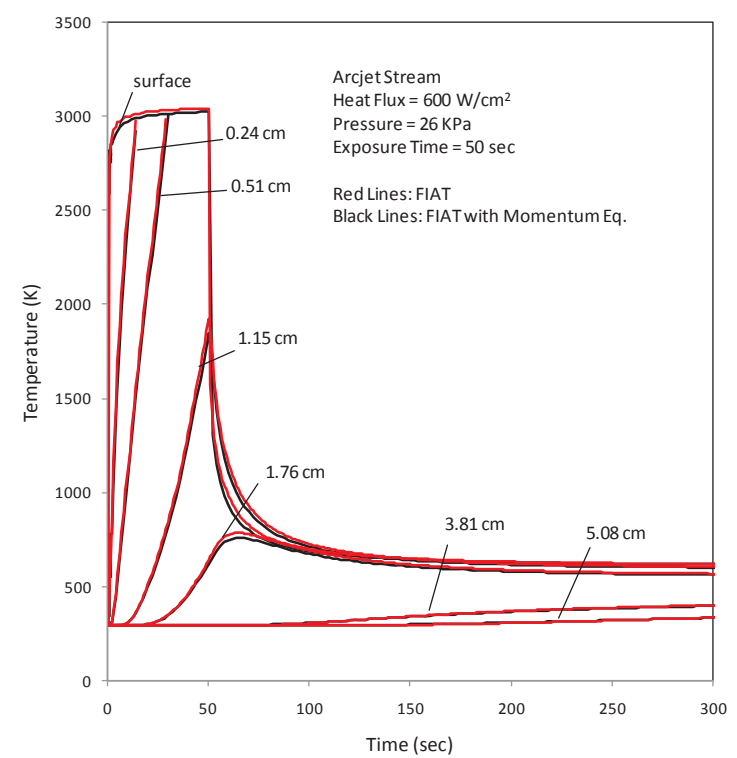

Figure 10b: Surface and in-depth temperatures predicted by baseline FIAT and by enhanced FIAT with chemical equilibrium chemistry for heat flux of $600 \mathrm{~W} / \mathrm{cm}^{2}$ and pressure of $26 \mathrm{kPa}$

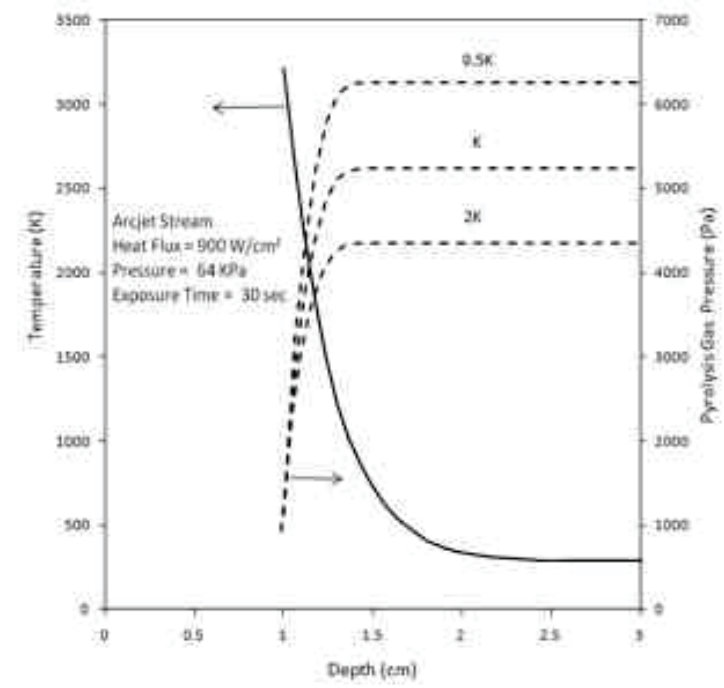

Figure 11a: Temperature and gas pressure profiles for heat flux of $900 \mathrm{~W} / \mathrm{cm}^{2}$ and pressure of $64 \mathrm{kPa}$ at time equal to $30 \mathrm{sec}$

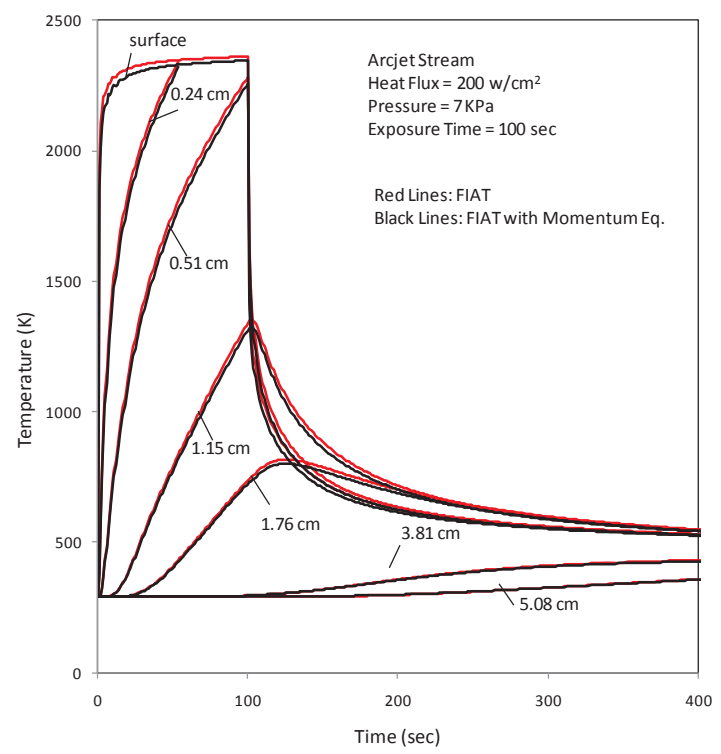

Figure 10c: Surface and in-depth temperatures predicted by baseline FIAT and by enhanced FIAT with chemical equilibrium chemistry for heat flux of $200 \mathrm{~W} / \mathrm{cm}^{2}$ and pressure of $7 \mathrm{kPa}$

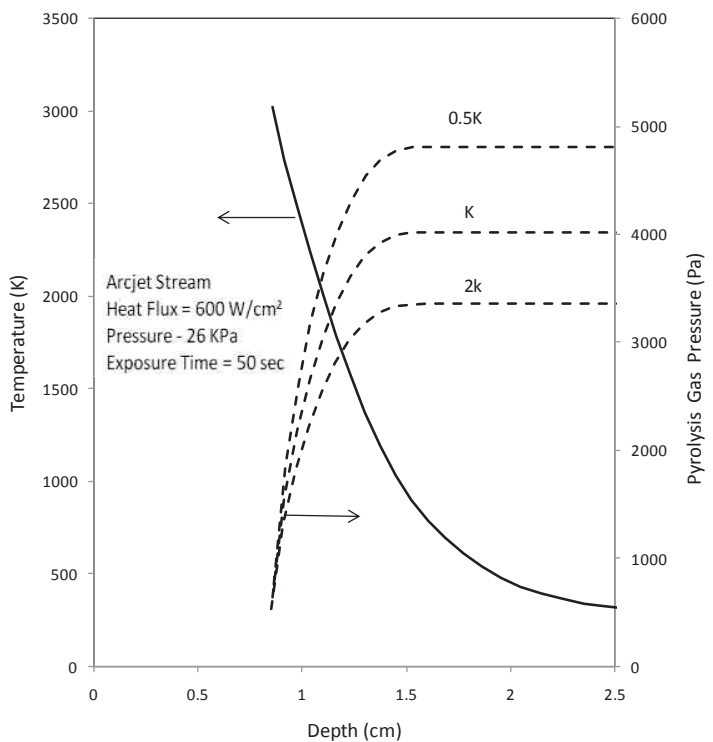

Figure 11b: Temperature and gas pressure profiles for heat flux of $600 \mathrm{~W} / \mathrm{cm}^{2}$ and pressure of $26 \mathrm{kPa}$ at time equal to $50 \mathrm{sec}$ 


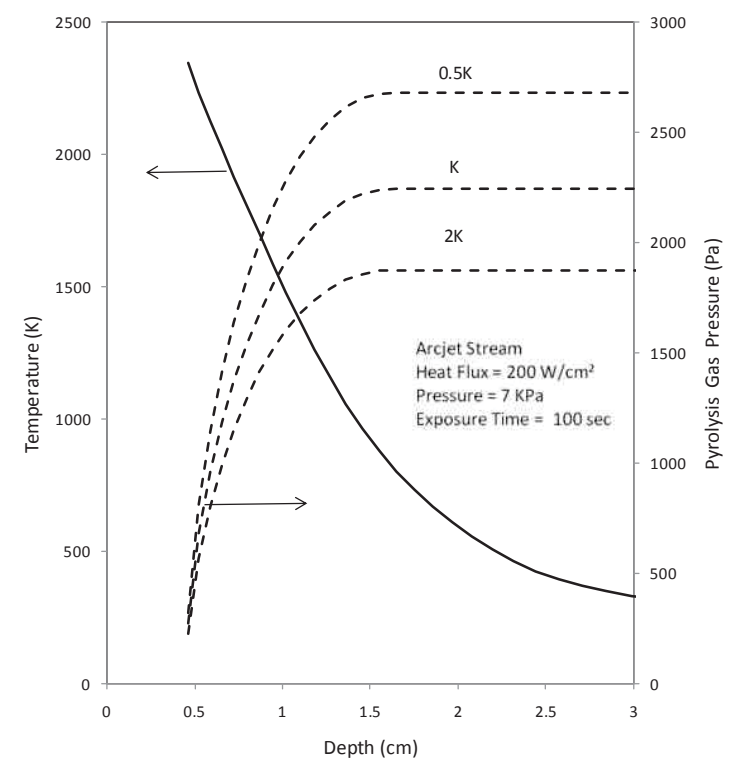

Figure 11c: Temperature and gas pressure profiles for heat flux of $200 \mathrm{~W} / \mathrm{cm}^{2}$ and pressure of $7 \mathrm{kPa}$ at time equal to $100 \mathrm{sec}$

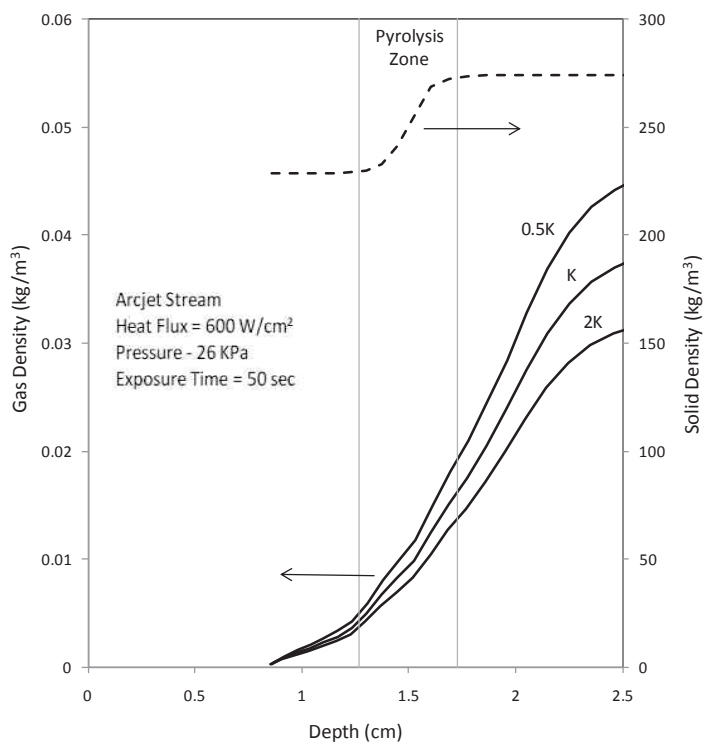

Figure 12b: Gas density and solid density profiles for heat flux of $600 \mathrm{~W} / \mathrm{cm}^{2}$ and pressure of $26 \mathrm{kPa}$ at time equal to $50 \mathrm{sec}$

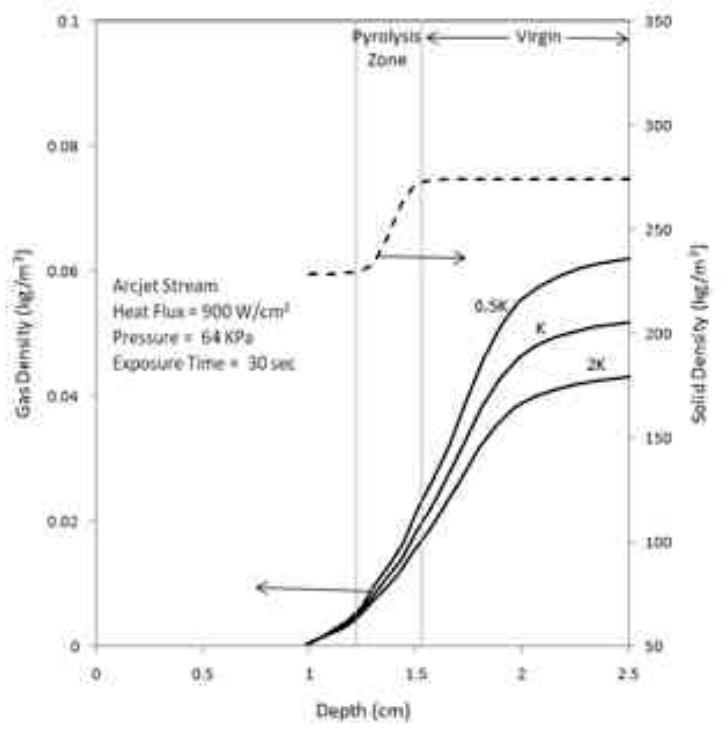

Figure 12a: Gas density and solid density profiles for heat flux of $900 \mathrm{~W} / \mathrm{cm}^{2}$ and pressure of $64 \mathrm{kPa}$ at time equal to $30 \mathrm{sec}$

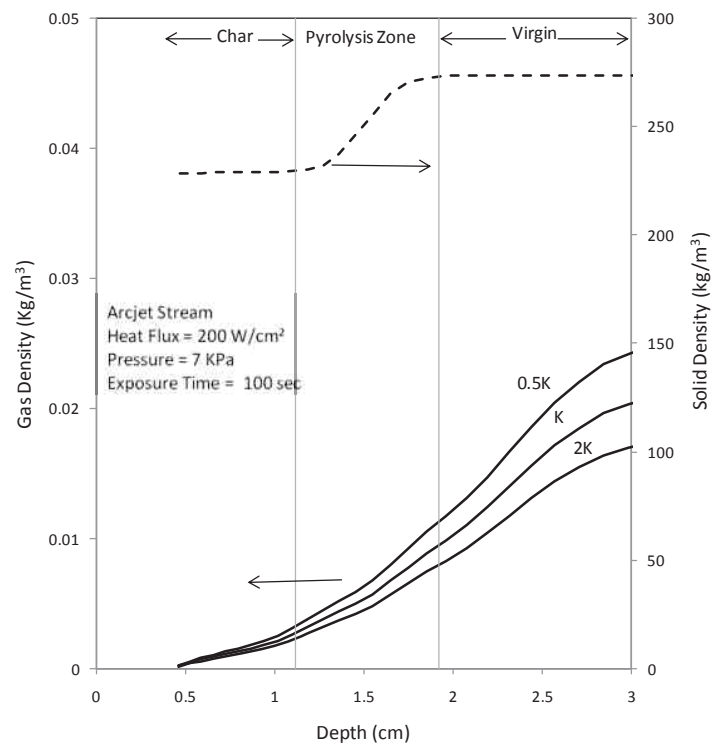

Figure 12c: Gas density and solid density profiles for heat flux of $200 \mathrm{~W} / \mathrm{cm}^{2}$ and pressure of $7 \mathrm{kPa}$ at time equal to $100 \mathrm{sec}$ 


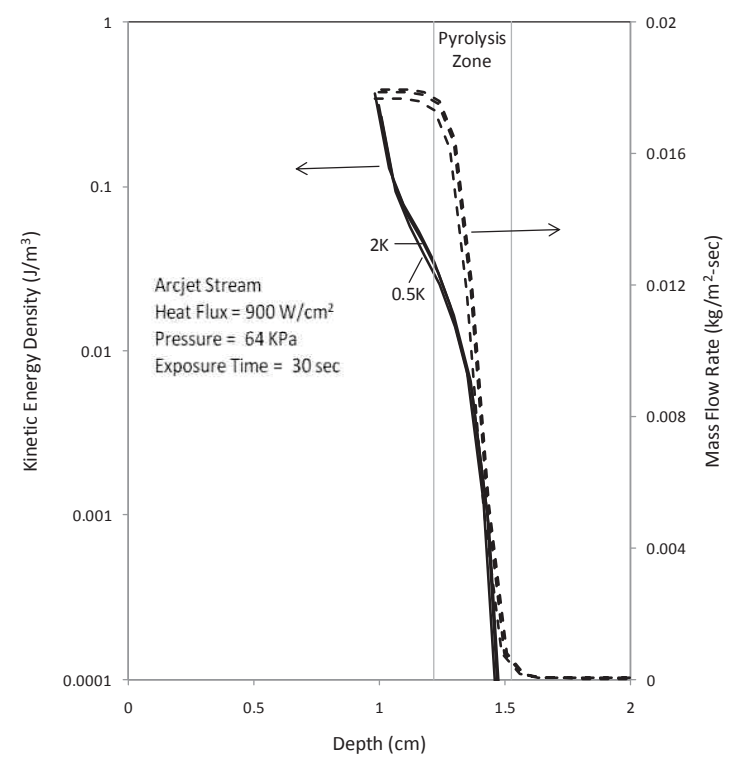

Figure 13a: Kinetic energy density and mass flow rate profiles for heat flux of $900 \mathrm{~W} / \mathrm{cm}^{2}$ and pressure of $64 \mathrm{kPa}$ at time equal to $30 \mathrm{sec}$

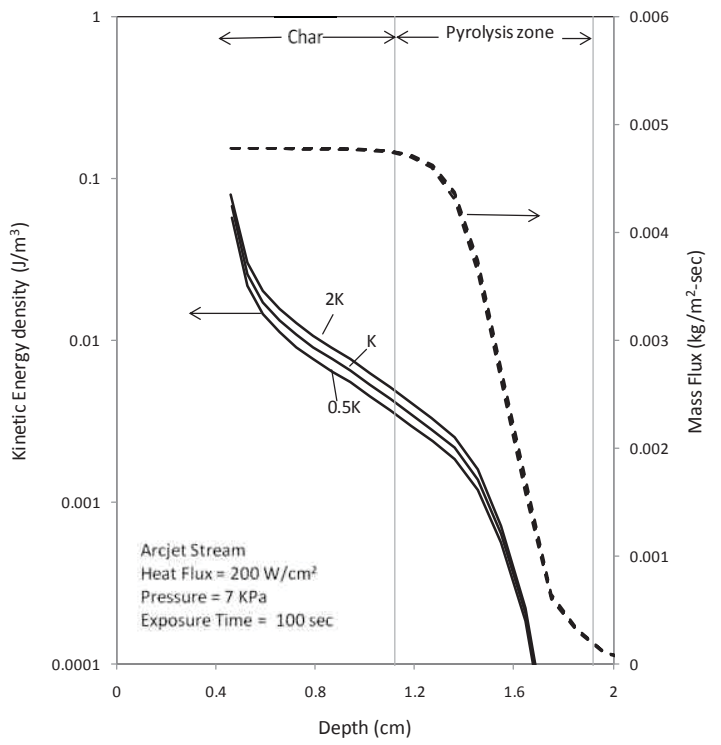

Figure 13c: Kinetic energy density and mass flow rate profiles for heat flux of $200 \mathrm{~W} / \mathrm{cm}^{2}$ and pressure of $7 \mathrm{kPa}$ at time equal to $100 \mathrm{~s}$

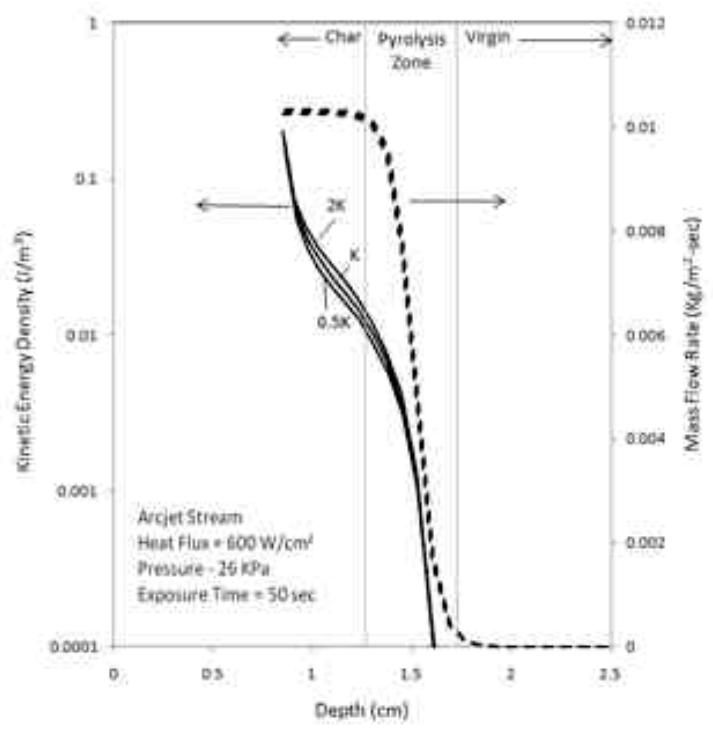

Figure 13b: Kinetic energy density and mass flow rate profiles for heat flux of $600 \mathrm{~W} / \mathrm{cm}^{2}$ and pressure of $26 \mathrm{kPa}$ at time equal to $50 \mathrm{sec}$

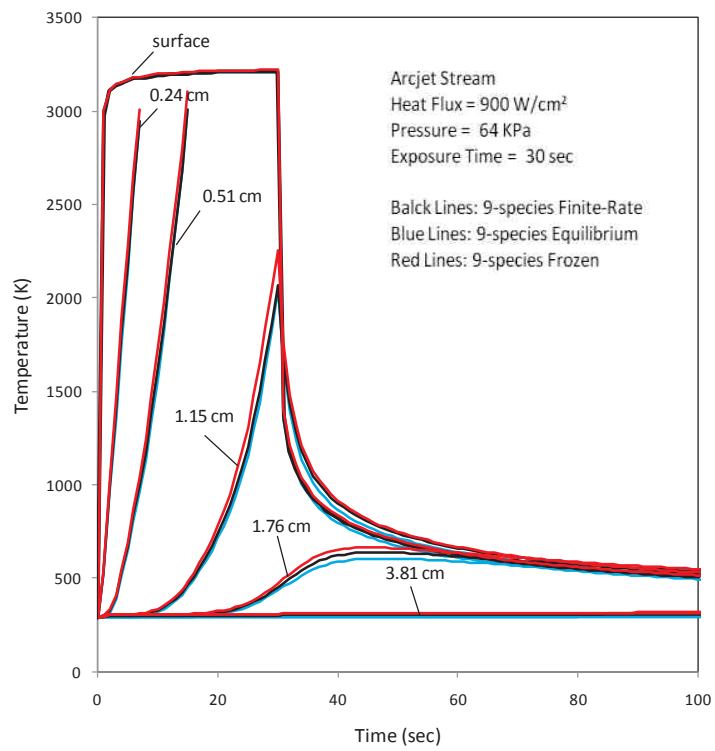

Figure 14a: Surface and in-depth temperatures predicted by finite-rate, equilibrium, and frozen gas chemistry models for heat flux of $900 \mathrm{~W} / \mathrm{cm}^{2}$ and pressure of $64 \mathrm{kPa}$ 


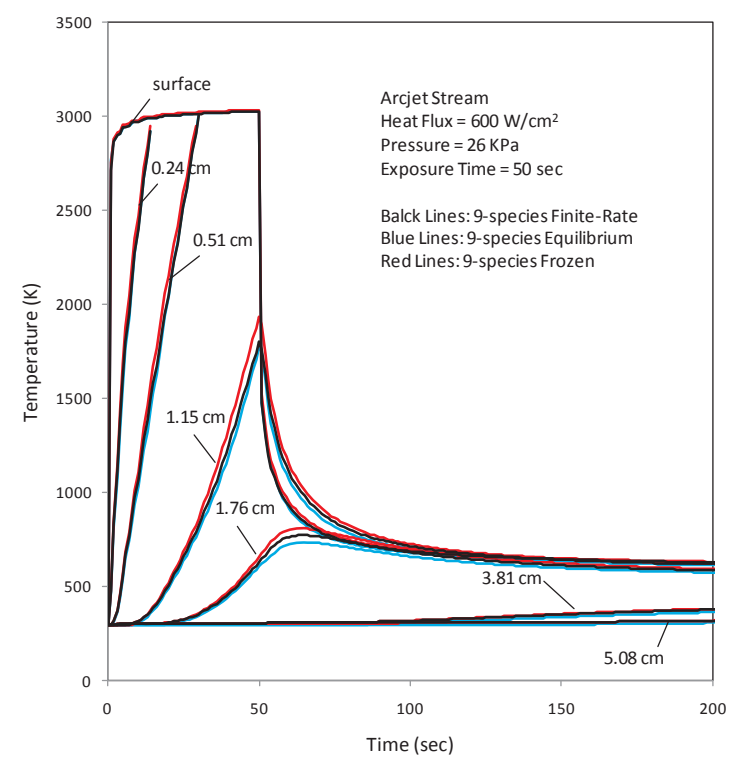

Figure 14b: Surface and in-depth temperatures predicted by finite-rate, equilibrium, and frozen gas chemistry models for heat flux of $600 \mathrm{~W} / \mathrm{cm}^{2}$ and pressure of $26 \mathrm{kPa}$

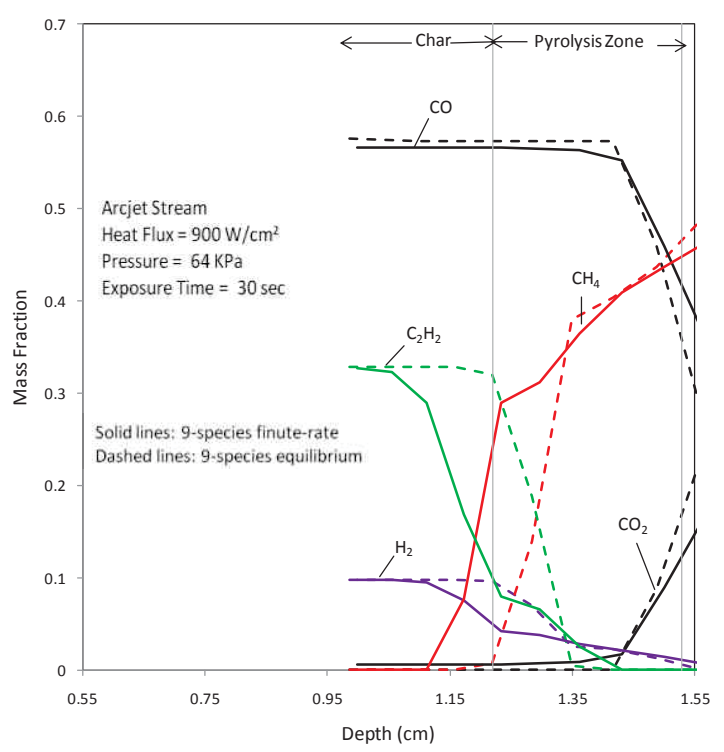

Figure 15a: Mass fraction profiles predicted by finite-rate and chemical equilibrium chemistry models for heat flux of $900 \mathrm{~W} / \mathrm{cm}^{2}$ and pressure of $64 \mathrm{kPa}$ at time equal to $30 \mathrm{sec}$

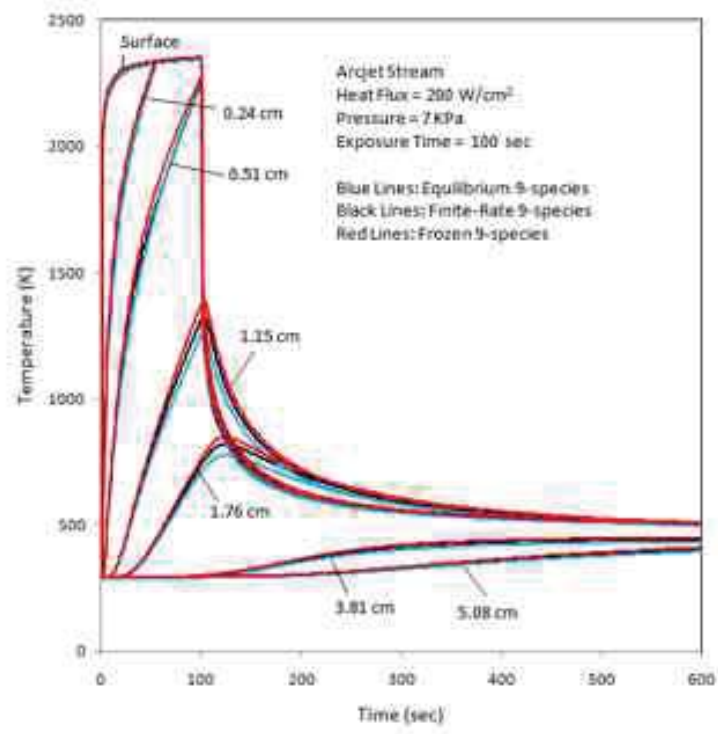

Figure 14c: Surface and in-depth temperatures predicted by finite-rate, equilibrium, and frozen gas chemistry models for heat flux of $200 \mathrm{~W} / \mathrm{cm}^{2}$ and pressure of $7 \mathrm{kPa}$

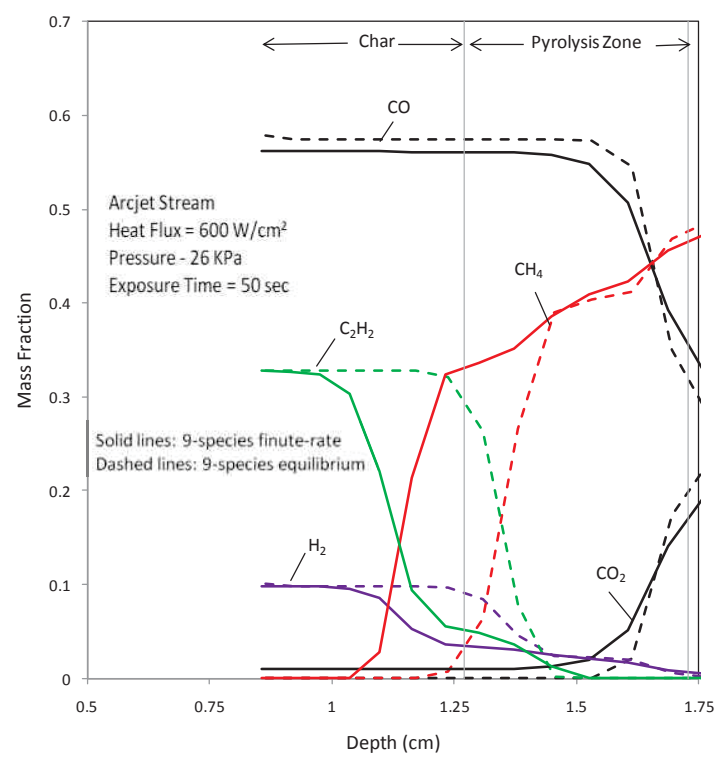

Figure 15b: Mass fraction profiles predicted by finite-rate and chemical equilibrium chemistry models for heat flux of $600 \mathrm{~W} / \mathrm{cm}^{2}$ and pressure of $26 \mathrm{kPa}$ at time equal to $50 \mathrm{sec}$ 


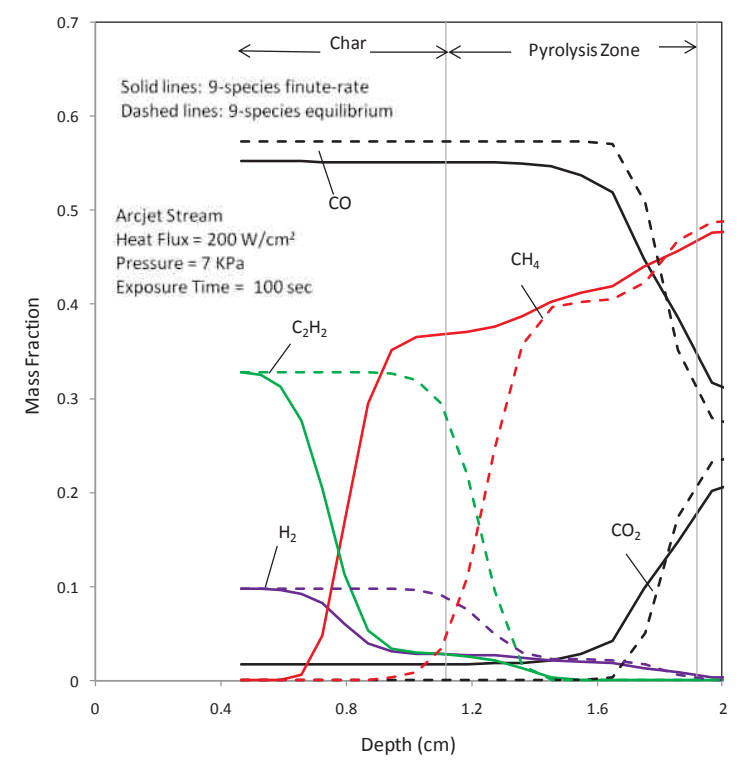

Figure 15c: Mass fraction profiles predicted by finiterate and chemical equilibrium chemistry models for heat flux of $200 \mathrm{~W} / \mathrm{cm}^{2}$ and pressure of $7 \mathrm{kPa}$ at time equal to $100 \mathrm{sec}$ 